\title{
Aeroservoelastic Wind-Tunnel Tests of a Free-Flying, Joined-Wing SensorCraft Model for Gust Load Alleviation
}

\author{
Robert C. Scott, ${ }^{*}$ Mark A. Castelluccio, ${ }^{\dagger}$ \\ David A. Coulson, ${ }^{\ddagger}$ and Jennifer Heeg ${ }^{\S}$
}

\begin{abstract}
A team comprised of the Air Force Research Laboratory (AFRL), Boeing, and the NASA Langley Research Center conducted three aeroservoelastic wind-tunnel tests in the Transonic Dynamics Tunnel to demonstrate active control technologies relevant to large, flexible vehicles. In the first of these three tests, a full-span, aeroelastically scaled, windtunnel model of a joined-wing SensorCraft vehicle was mounted to a force balance to acquire a basic aerodynamic data set. In the second and third tests, the same wind-tunnel model was mated to a new, two-degree-of-freedom, beam mount. This mount allowed the fullspan model to translate vertically and pitch. Trimmed flight at $\mathbf{- 1 0 \%}$ static margin and gust load alleviation were successfully demonstrated. The rigid body degrees of freedom required that the model be flown in the wind tunnel using an active control system. This risky mode of testing necessitated that a model arrestment system be integrated into the new mount. The safe and successful completion of these free-flying tests required the development and integration of custom hardware and software. This paper describes the many systems, software, and procedures that were developed as part of this effort. The balance and free flying wind-tunnel tests will be summarized. The design of the trim and gust load alleviation control laws along with the associated results will also be discussed.
\end{abstract}

\section{Nomenclature}

$\begin{array}{ll}\text { A/D } & \text { Analog to Digital } \\ \text { AEI } & \text { Aerodynamic Efficiency Improvement } \\ \text { AFRL } & \text { Air Force Research Laboratory } \\ \text { AOS } & \text { Airstream Oscillation System } \\ \text { ASE } & \text { Aeroservoelasticity } \\ \text { AWI } & \text { Aft Wing Inboard } \\ \text { AWM } & \text { Aft Wing Midboard } \\ \text { AWO } & \text { Aft Wing Outboard } \\ \text { azMode } & \text { Flight control parameter used internally to select which trim control loops operate } \\ \text { BNC } & \text { Bayonet Neill-Concelman connector } \\ \text { CG } & \text { Center of Gravity, referred to throughout the paper in terms of the resulting static margin, } \\ & \text { percent mean aerodynamic chord } \\ \text { CS } & \text { Control Surface } \\ \text { D/A } & \text { Digital to Analog } \\ \text { DAS } & \text { Data Acquisition System } \\ \text { DCS } & \text { Digital Control System } \\ \text { DOF } & \text { Degree of Freedom } \\ \text { dSpace1 } & \text { DCS for Servo PID loops and WatchDog } \\ \text { dSpace2 } & \text { DCS for Trim \& GLA }\end{array}$

*Senior Aerospace Engineer, Aeroelasticity Branch, NASA Langley Research Center, Hampton, VA, AIAA Associate Fellow.

$\dagger^{\dagger}$ Guidance, Navigation \& Control Engineer, The Boeing Company, Seattle, WA.

${ }^{\ddagger}$ Senior Research Engineer, Analytical Services \& Materials, Inc., Hampton, VA.

$\S$ Senior Aerospace Engineer, Aeroelasticity Branch, NASA Langley Research Center, Hampton, VA, AIAA Senior Member. 


\begin{tabular}{|c|c|}
\hline FlightMode & Flight Mode \\
\hline FWO & Forward Wing Outboard \\
\hline FWM & Forward Wing Midboard \\
\hline FWI & Forward Wing Inboard \\
\hline GLA & Gust Load Alleviation \\
\hline GLAMode & User input for GLA control law selection \\
\hline gpm & gallons per minute \\
\hline GUI & Graphical User Interface \\
\hline HiLDA & High Lift over Drag Active Wing \\
\hline $\mathrm{H}_{o}$ & TDT total pressure, psf \\
\hline JWS & Joined Wing SensorCraft \\
\hline LESP & Leading Edge Stagnation Point Sensor \\
\hline $\mathrm{M}_{F W O}$ & GLA output mix value for forward wing outboard surfaces \\
\hline $\mathrm{M}_{A W I}$ & GLA output mix value for aft wing inboard surfaces \\
\hline ParamID & Parameter Identification \\
\hline PID & Proportional Integral Derivative \\
\hline PilotIn & User input for initiating model launch or landing \\
\hline PSNUB & Snub signal for pitch snub mechanism \\
\hline PTHETA & Model pitch angle also referred to as $\Theta$, degrees \\
\hline $\mathrm{PZ}$ & Vertical position ( $\mathrm{PZ}=0$ at centerline), in \\
\hline $\mathrm{PZ}_{\text {Center }}$ & Parameter used in fault detection algorithm, in \\
\hline $\mathrm{PZ}_{C m d}$ & $\mathrm{PZ}$ set point for trim controller, in \\
\hline $\mathrm{PZ}_{\text {Range }}$ & Parameter used in fault detection algorithm, in \\
\hline Reset & User input for resetting control systems in preparation for model launch \\
\hline RUD & Rudder \\
\hline SGFWLI & Strain Gauge Forward Wing Left Inboard, microstrain \\
\hline SGFWRI & Strain Gauge Forward Wing Right Inboard, microstrain \\
\hline SGTF & Strain Gauge Tail Forward (or root), microstrain \\
\hline SGTM & Strain Gauge Tail Mid, microstrain \\
\hline SGTA & Strain Gauge Tail Aft, microstrain \\
\hline RVDT & Rotary Variable Differential Transducer \\
\hline Snub! & Command to engage snubbing system \\
\hline SNBXSTAT & Signal indicating state of snubber control system relays \\
\hline TestMode & User input for selecting the type of ParamID testing \\
\hline TDT & Transonic Dynamic Tunnel \\
\hline $\mathrm{V}$ & Volts \\
\hline VZ & Vertical velocity, in/s \\
\hline $\mathrm{VZ}_{\text {Limit }}$ & Parameter used in fault detection algorithm, in $/ \mathrm{s}$ \\
\hline WatchDog & Software for triggering Snub! command \\
\hline ZSNUB & Snub signal for brake \\
\hline$\delta_{C m d}$ & Wing control surface and rudder position commands, degrees \\
\hline$\delta_{C S}$ & Wing control surface positions, degrees \\
\hline$\delta_{\text {Rudder }}$ & Rudder position, degrees \\
\hline$\Theta$ & Model pitch angle also referred to as PTHETA, degrees \\
\hline$\Theta_{\text {Center }}$ & Parameter used in fault detection algorithm, degrees \\
\hline$\Theta_{\text {Range }}$ & Parameter used in fault detection algorithm, degrees \\
\hline$\Theta_{C m d}$ & $\Theta$ set point for trim controller THETA loop, degrees \\
\hline$\dot{\Theta}$ & Pitch rate, $\mathrm{deg} / \mathrm{s}$ \\
\hline$\dot{\Theta}_{\text {Limit }}$ & Parameter used in fault detection algorithm, degrees/s \\
\hline
\end{tabular}

\section{Introduction}

A goal of the Air Force Research Laboratory's SensorCraft project is to develop technologies for future high-altitude long-endurance unmanned surveillance platforms. Two research programs intended to develop 
technologies relevant to these large, flexible vehicles are the High-Lift-over-Drag Active (HiLDA) Wing and the Aerodynamic Efficiency Improvement (AEI) programs. ${ }^{1}$ The goals of the HiLDA and AEI programs included the demonstration of Gust Load Alleviation (GLA), an enabling technology for a SensorCraft vehicle that will allow it to have reduced structural weight thereby increasing endurance, range, and payload capacity.

\begin{tabular}{|c|c|c|c|c|c|c|c|c|}
\hline & FYO3 & FYO4 & FY05 & FYOG & FY07 & FY08 & FYOg & FY10 \\
\hline $\begin{array}{l}\text { HiLDA } \\
\text { T574: NASA } \\
\text { T579: Northrop Grumman }\end{array}$ & & & & & & & & \\
\hline $\begin{array}{l}\text { AEl } \\
\text { T593: Northrop Grumman } \\
\text { T598: Northrop Grumman \& } \\
\quad \text { Lockheed Martin } \\
\text { T606: Boeing } \\
\text { T613: Boeing } \\
\text { T614: Boeing }\end{array}$ & & & & & 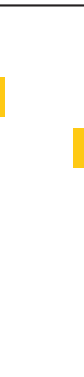 & & | & 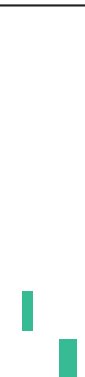 \\
\hline
\end{tabular}

Figure 1. NASA Langley Transonic Dynamics Tunnel tests for the HiLDA and AEI programs.

Several HiLDA and AEI aeroservoelastic wind-tunnel tests were conducted in the NASA Langley Transonic Dynamics Tunnel (TDT) and are depicted in figure 1. The first two wind-tunnel tests were conducted as part of the HiLDA program. These included a short test of several candidate sensors for measuring gust flow angle. The HiLDA flying-wing was tested in September 2004 with gust load alleviation being demonstrated on a cantilevered mount using the model's five active control surfaces. ${ }^{2-4}$ This test configuration is shown in figure $2 \mathrm{a}$.

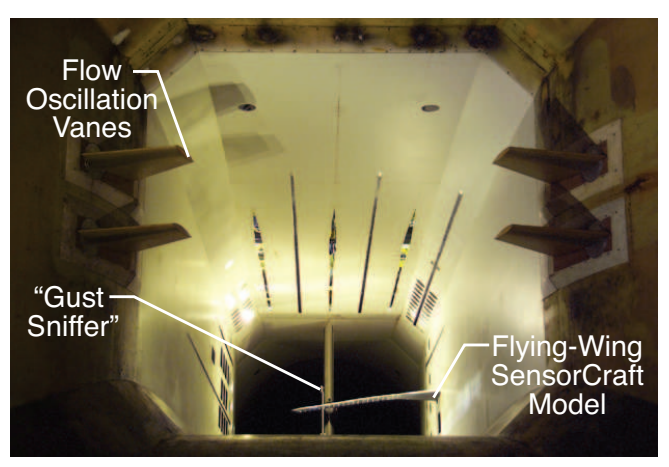

(a) Photo of TDT test 579 configuration showing the AOS vanes and the flying-wing attached to the balance.

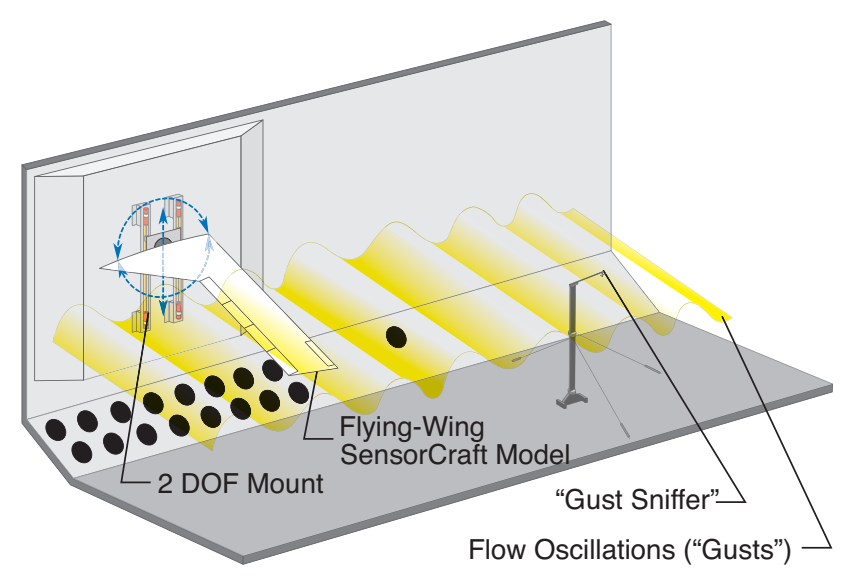

(b) Illustration of the flying-wing SensorCraft model mated to a two degree-of-freedom sidewall support system.

Figure 2. Flying-wing SensorCraft model TDT test configurations.

While not originally designed for this purpose, the HiLDA flying-wing model was mated to a new, two-degree-of-freedom mount and retested in support of the AEI program in 2007 . This mount allowed the half-span model to translate vertically and pitch at the wing root, allowing the model to "fly" in the tunnel providing a simulation of the full-span vehicle's rigid-body modes. The large size of the flying wing 
model along with the rigid body degrees-of-freedom afforded by the new mount system, created many unique challenges to successfully and safely conducting the test. A remotely actuated snubbing system that returned the model to a fixed pitch angle was included in the mount design. Determining how to effectively use this system was critical to the success of these tests, and applicable systems and procedures are described in reference 5. Figure $2 \mathrm{~b}$ depicts the flying-wing and mount system in the final configuration used in Test 598 where GLA and body freedom flutter suppression control laws were successfully demonstrated. ${ }^{5-9}$ The Joined-Wing SensorCraft (JWS) wind-tunnel tests built on the systems, procedures, and lessons learned from the flying-wing tests.

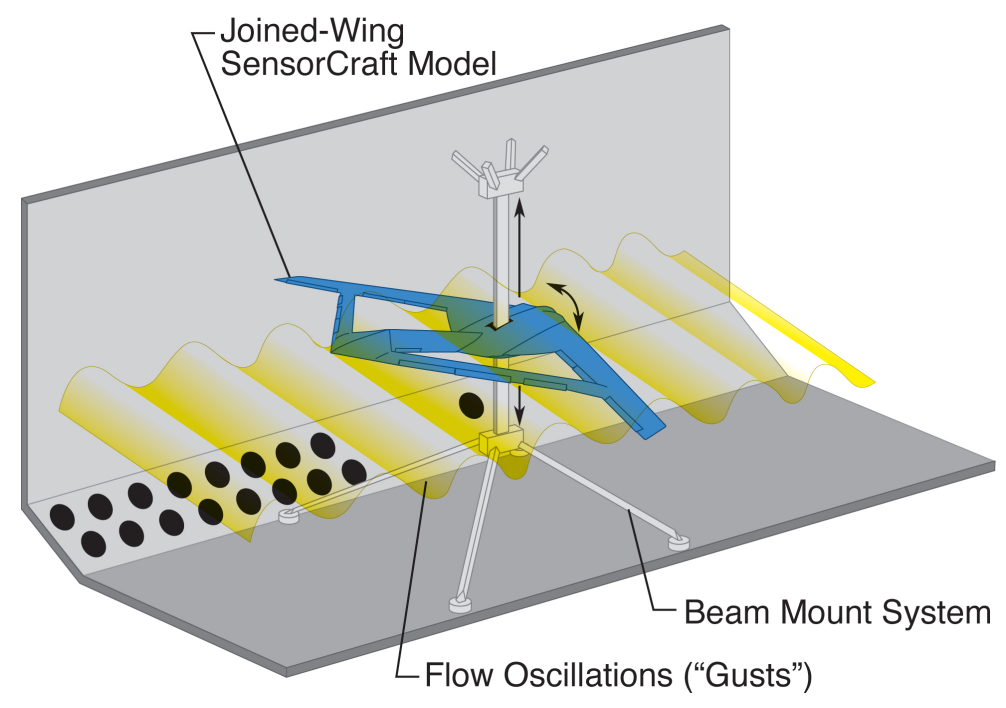

Figure 3. Illustration of the AEI Joined-Wing SensorCraft model mated to a two degree-of-freedom support system installed in the NASA Langley Transonic Dynamics Tunnel.

As shown in figure 1, three tests of the JWS ${ }^{10,11}$ were conducted. During the first test (TDT test 606, December 2008) the model was installed on the TDT sting with a balance, and a basic aerodynamic data set was acquired in air and heavy gas. During the second and third tests a new beam mount, shown in figure 3, was used. The beam mount along with a carriage assembly installed inside the model provide pitch and plunge degrees of freedom allowing the model to "fly" in the TDT test section. The carriage design incorporates model arrestment systems that include a plunge brake and a pitch displacement limiter. During the second test operation of the trim control law was verified and Parameter Identification (ParamID) data was acquired. Gust Load Alleviation (GLA) was demonstrated during the third test.

Reference 12 provides a detailed description of the objectives for the JWS wind-tunnel test program. The primary objectives were to demonstrate stable controlled flight at $-10 \%$ static stability; measure stability margins while flying; and reduce gust loads of the first symmetric structural mode by $50 \%$ and of the second symmetric structural mode by $20 \%$. These objectives were achieved with the exception of reductions of the loads of the second structural mode. This objective was not attempted due to the limited accuracy of the simulation models at the higher frequencies. A real-time stability margin test mode was successfully implemented and used throughout testing to determine the phase and gain margins of several of the key controller loops within the flight control system. These stability margin measurements were used to verify the modeling used to design the control laws.

An overview of the JWS project is provided in reference 13. The wind-tunnel model and mount system are described in references 14 and 15, respectively, and reference 16 covers some ParamID research that is not covered here. The purpose of this paper is to provide an overview of the AEI Joined-Wing SensorCraft wind-tunnel tests focusing on systems, procedures, control law development, and results. The main focus of this paper will be on the dynamic testing conducted during TDT tests 613 and 614 . However, a summary of the basic aerodynamic test (TDT Test 606) is also included in the appendix for completeness. 


\section{Transonic Dynamics Tunnel and the Airstream Oscillation System}

The Langley Transonic Dynamics Tunnel (TDT), depicted in figure 4a, is a unique national facility dedicated to identifying, understanding, and solving relevant aeroelastic and aeroservoelastic problems. The TDT is a closed-circuit, continuous-flow, variable-pressure, wind tunnel with a 16 -foot square test section with cropped corners. ${ }^{17}$ The tunnel uses either air or a heavy gas as the test medium and can operate at total pressures from near vacuum to atmospheric. It has a Mach number range from near zero to 1.2 and is capable of maximum Reynolds numbers of about 3 million per foot in air and 10 million per foot in heavy gas. Until 1996, the TDT used dichlorodifluoromethane, R-12, as the heavy gas test medium; since then the TDT has used 1,1,1,2 tetrafluoroethane, R-134a ${ }^{18,19}$ an environmentally acceptable alternative to R-12.

The TDT is specially configured for flutter testing, with excellent model visibility from the control room and a rapid tunnel shutdown capability for model safety. Testing in heavy gas has important advantages over testing in air: improved model to full-scale similitude (which results in heavier, easier-to-build models with lower elastic mode frequencies), higher Reynolds numbers, and reduced tunnel power requirements.

Due to the need to perform GLA testing as part of the AEI program, the TDT Airstream Oscillation System (AOS) was used frequently. The key features of the AOS system are shown in the illustration in figure $4 \mathrm{~b}$. These features include biplane arrangements of vanes on either side of the entrance to the test section. Each pair of vanes is driven by a separate hydraulic motor and a flywheel to hold constant vane frequency. While the two pairs of vanes can be run out of phase, this was not done in the AEI test. Vane frequency was adjusted from the TDT control room manually or by using a LabView control system. The amplitude of the vanes is manually adjustable from $0^{\circ}$ to $12^{\circ}$ peak-to-peak. In order to reduce model risk, the vanes were set to $4^{\circ}$ peak-to-peak at the start of Test 613 . Soon after the start of Test 613 it was determined that the JWS model could accommodate the full $12^{\circ}$ peak-to-peak setting. Thus, the vast majority of data acquired during Test 613 and all of the data acquired during Test 614 used this setting. This setting results in a $\pm 1^{\circ}$ variation in stream angle in the vicinity of the model for low frequency oscillations; the amplitude rolls off with increasing frequency.

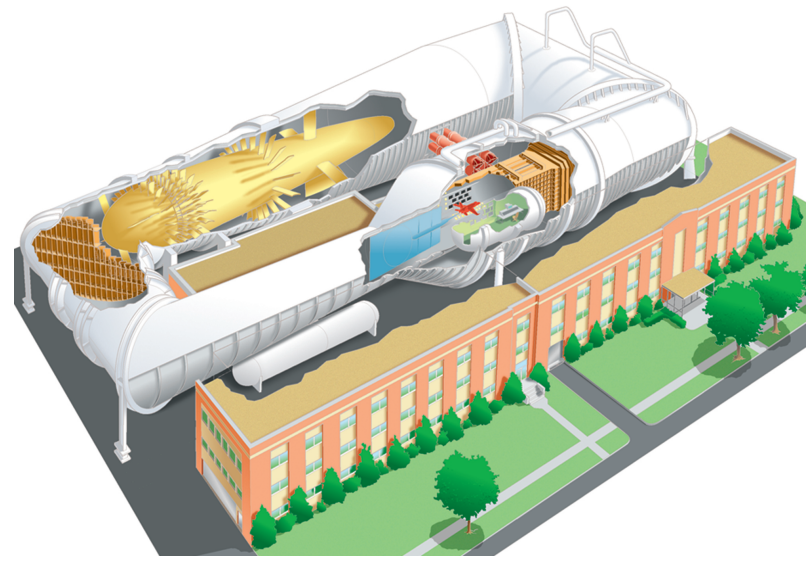

(a) TDT.

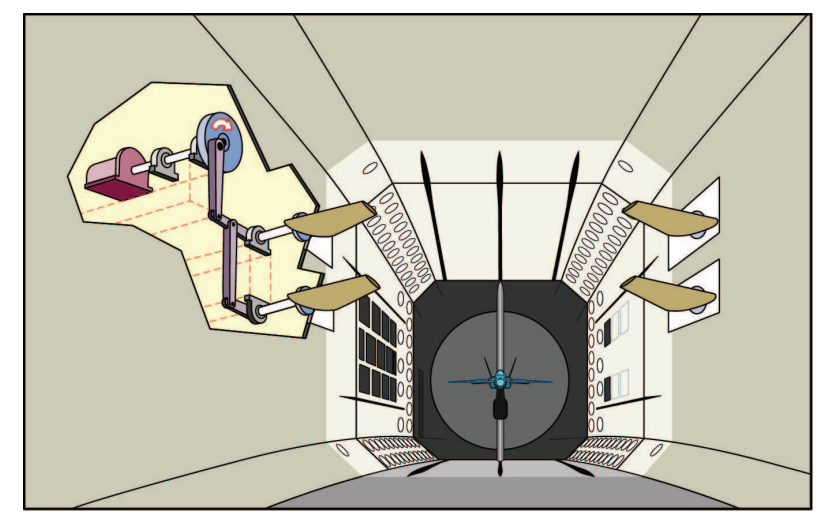

(b) AOS.

Figure 4. Illustration of the NASA Langley Transonic Dynamics Tunnel (TDT) and associated Airstream Oscillation System (AOS) used to conduct the JWS tests.

Figure 5a and $\mathrm{b}$ show the close-up views of the TDT air and R134a operation envelopes, respectively. The red lines represent the regions traversed when conducting the joined-wing tests. The red dots indicate the specific Mach number and dynamic pressure conditions where virtually all the relevant joined-wing data was acquired. In all cases the nominal dynamic pressure was $51 \mathrm{psf}$ with a Mach number of 0.195 in air and 0.220 in R134a. To verify model stability, flutter clearance runs were conducted in both test mediums for both the sting and the beam mount configurations. This testing involved increasing the dynamic pressure to 55 psf, slightly above the nominal test condition. During these clearance runs, model response was given a high degree of scrutiny. Flutter clearance is indicated in figure 5 by the red lines extending above the nominal test value of 51 psf.

Finally, it should be pointed out that while the model was scaled for testing in R134a, it is common practice to perform air checkout runs in the TDT prior to filling it with heavy gas. At the tunnel pressures 
used, tunnel preparation time for air testing was approximately $30 \mathrm{~min}$, while preparation time for heavy gas was approximately $7 \mathrm{hr}$. Returning the tunnel to a condition where personnel could enter the test section took comparable amounts of time. Thus, basic functionality of all systems was verified in air prior to beginning the R134a testing.

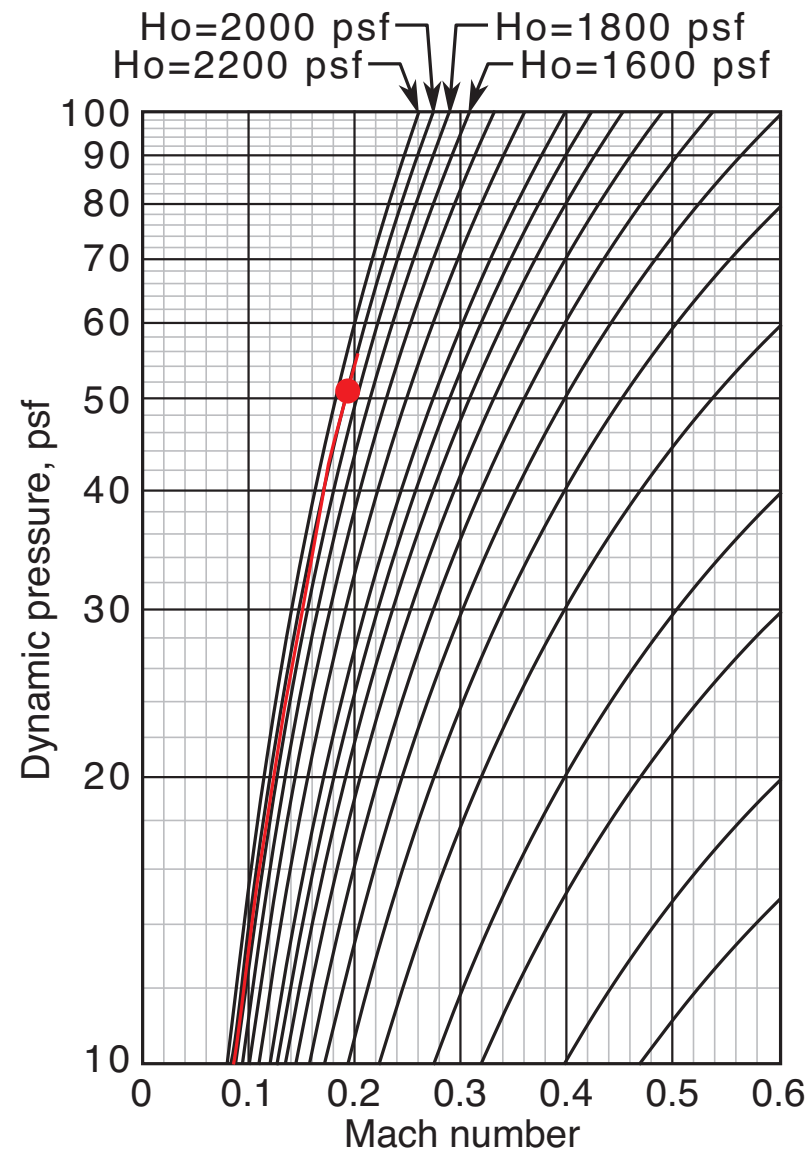

(a) Air.

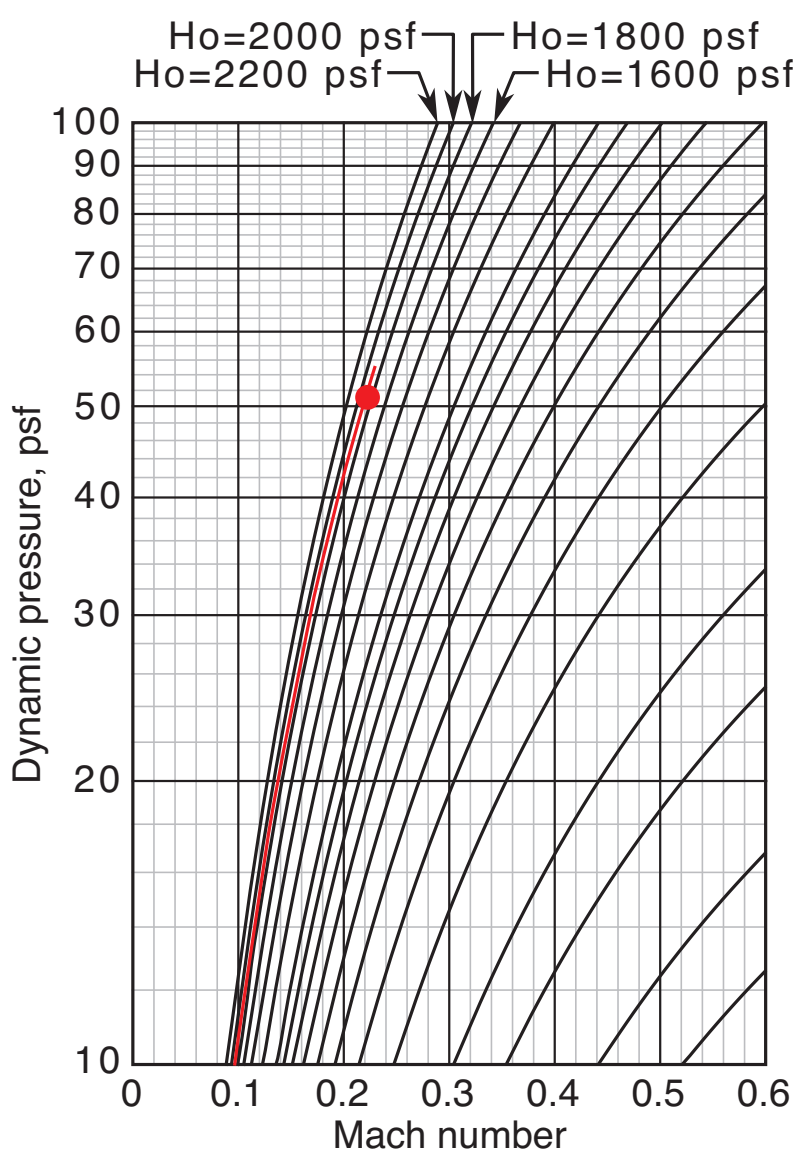

(b) R134a.

Figure 5. Close-up views of the TDT Air and R134a operation envelopes showing the conditions where joined-wing testing was conducted.

\section{Model and Mount System Description}

The model is an 8\%-length scale, full-span, aeroelastically scaled model of a Boeing Joined-Wing SensorCraft design concept. The wings and tail boom use a spar-pod design where the scaled stiffnesses (EI and GJ distributions) are achieved by proper geometry of the metal spars, and the aerodynamic shape is provided by discrete fairings, or pods, mounted to the spar. Lead weights were attached to the spar to achieve the proper scaled mass distribution.

A planform drawing of the JWS model is shown in figure 6. As shown in the drawing, each wing has three pairs of trailing edge control surfaces and the tail boom has a rudder. The 13 control surfaces were driven by vane-type hydraulic actuators operated at 1,000 psi with position measured by Rotary Variable Differential Transducers (RVDTs). Other instrumentation included strain gauges, accelerometers, and rate gyros for fuselage pitch, roll, and yaw. A moving mass system was included in the fuselage that provided remote adjustment of the model CG. The device consisted of a compact DC motor coupled via a belt to two ball screws that each moved $13 \mathrm{lbs}$ of lead. Theses masses could move over a range of 26 inches. The position of these ballast weights was mapped to 4 CG locations associated with $+5 \%, 0 \%,-5 \%$, and $-10 \%$ static margin. Additional model details can be found in references 14 and 12 .

The beam support system along with a carriage assembly installed inside the model provide pitch and 


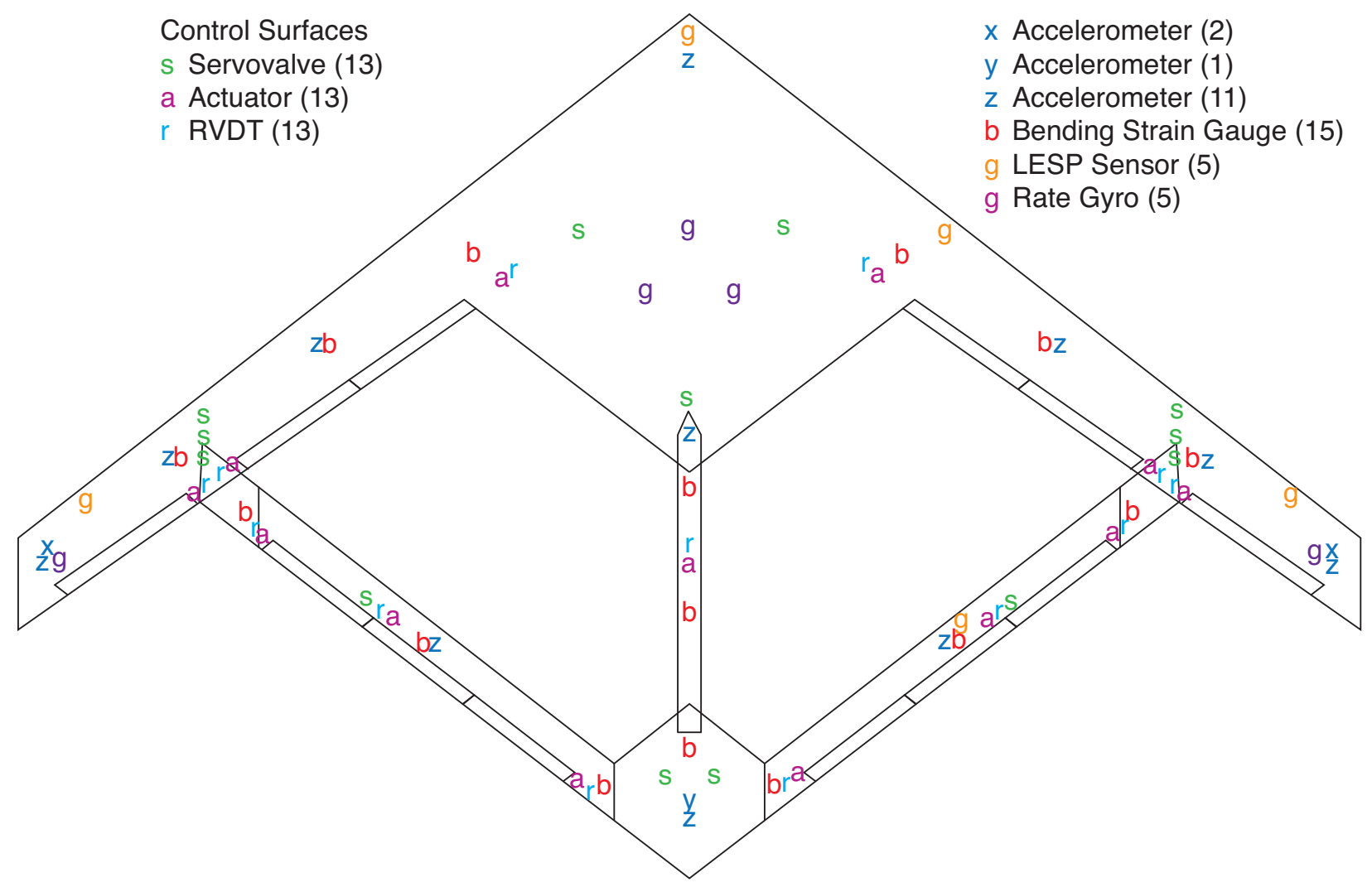

Figure 6. Joined-Wing SensorCraft model planform view showing onboard instrumentation, actuators, and servo valves. Accelerometer orientation: $\mathrm{x}=$ longitudinal, $\mathrm{y}=$ lateral, $\mathrm{z}=$ vertical. Fuselage gyros measure pitch, roll and yaw rates. Wing tip gyros measure local rotation rate. 


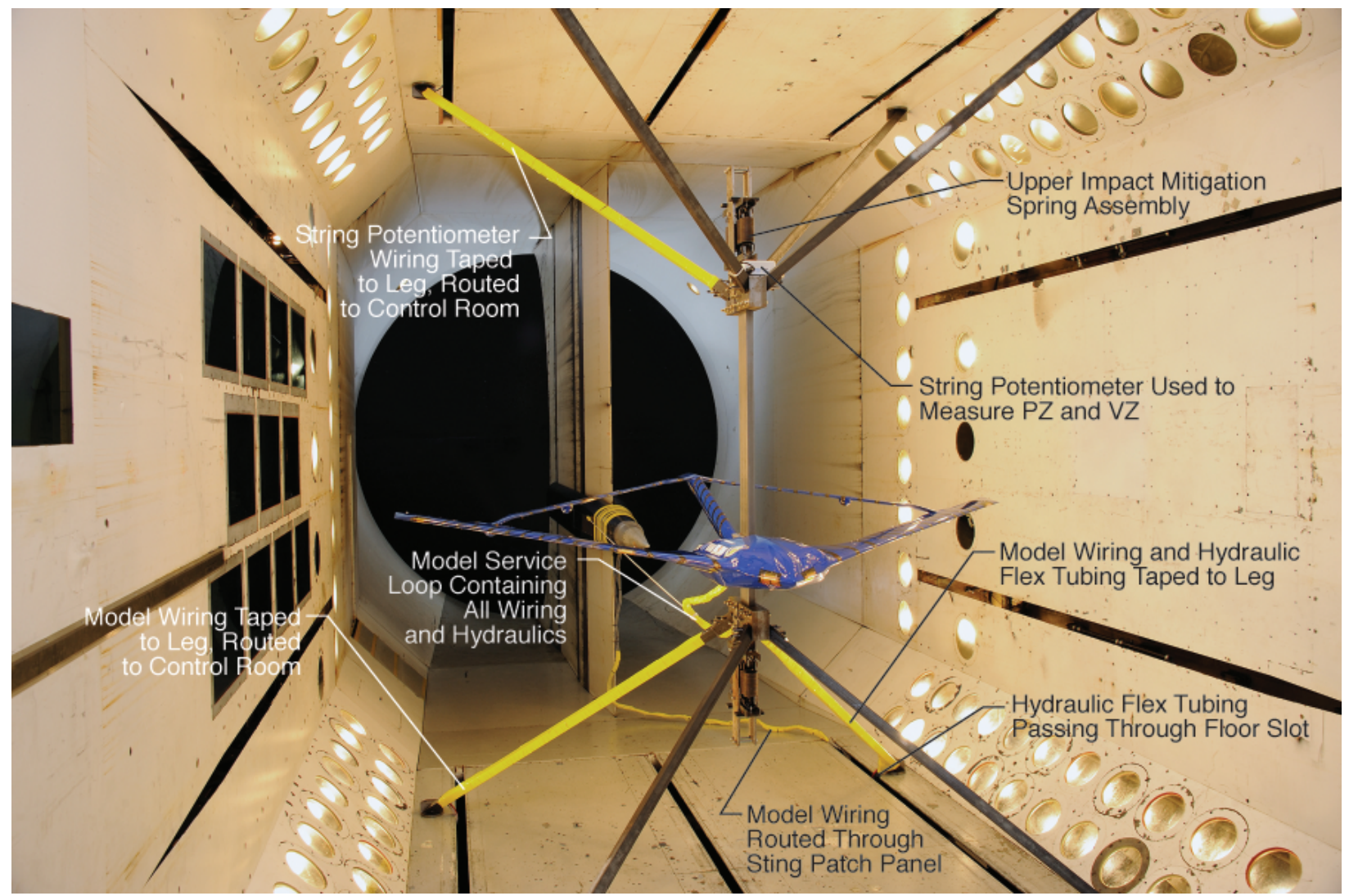

(a) Joined-wing SensorCraft model installed on the beam support

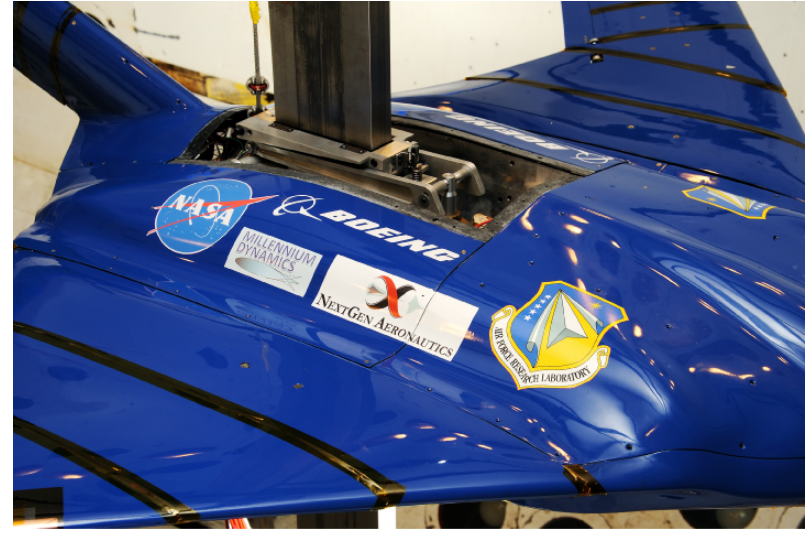

(b) Close up photograph of the joined wing model, carriage, and beam support.

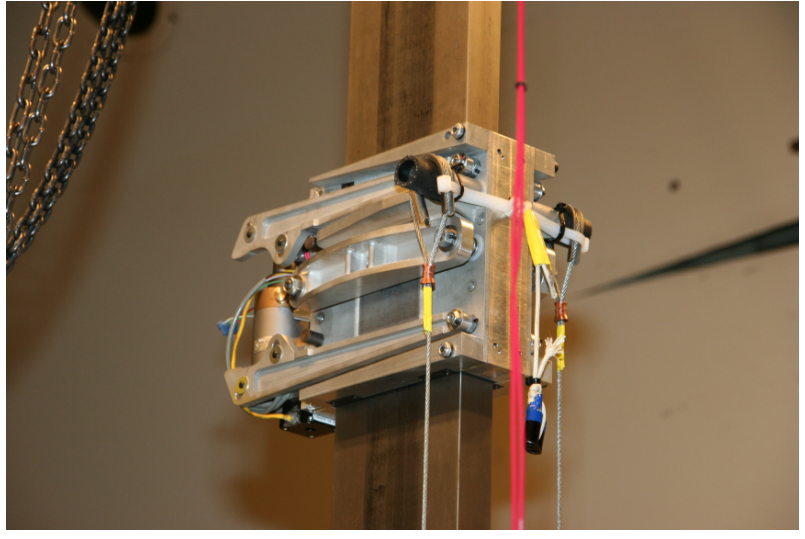

(c) Carriage installed on the beam support without the joinedwing model. The cables were used to support weights to test brake operation.

Figure 7. Joined-wing, beam support, and carriage assembly installed in the TDT for Tests 613 and 614.

plunge degrees of freedom allowing the model to "fly" in the TDT test section. The model installed on the carriage and beam support system is shown in figures $7 \mathrm{a}$ and $7 \mathrm{~b}$. As noted in the upper photo, a string potentiometer was used to measure PZ and VZ. The string potentiometer itself was mounted on the upper end of the beam with the string passing over a small pulley then along the downstream face of the beam where it attached to the carraige. The carriage design incorporates model arrestment systems that include a plunge brake and a pitch displacement limiter. The carriage is shown installed on the beam without the model in figure 7c. Additional details about the design and testing of the beam support system can be found in references 12 and 15 .

Due to the aeroservoelastic nature of these wind-tunnel tests, the frequency response of the control surface 
actuators was important both in terms of bandwidth and consistency. During the model design/fabrication process, a bench test rig was used to assess performance of a single actuator using the same components intended for the wind-tunnel model. Later, performance of all 13 actuators operating within the model was assessed and a number of changes had to be made to the model hydraulic system. The bench test experiments and subsequent performance in the wind-tunnel model will be discussed in the appendix.

Reference 12 describes a ground vibration test of the JWS model supported by soft springs that was performed at the TDT prior to the wind-tunnel tests. The first three symmetric flexible modes had frequencies of $4.57 \mathrm{~Hz}, 9.05 \mathrm{~Hz}$, and $12.75 \mathrm{~Hz}$. These modes are dominated by displacement that can best be described as forward wing 1st bending, forward wing 2 nd bending, and aft wing 1st bending, respectively.

\section{Model Signals, Conditioning, and Control}

This section of the paper will present several block diagrams showing increasing levels of detail on how the model signals were routed, conditioned, and controlled. The first of these diagrams shows how signals are routed to the model, the various signal conditioners, the control systems, and the data acquisition system. The next block diagram focuses on the two digital control systems and the snubber control system, and the third diagram focuses on the the flight control block. Some items in these diagrams will be described in greater detail in this section of the paper while others will be covered in separate sections. Within these diagrams, signals depicted in orange are operator inputs and those in red are snubber system related signals.

A high level schematic of the signal routing arrangement used in joined-wing tests is shown in figure 8. As shown, the input and output signals were routed from the model or mount system to the TDT control room via the control room-to-sting patch panel or directly to the control room via the plenum penetration. Most instrumentation was routed to a Pacific Instruments series 6000 chassis that provided instrument power (5 or 10 VDC), signal amplification, and anti-alias filtering. The fuselage mounted rate gyros required \pm 15 VDC power so a custom power supply was fabricated with the signals subsequently routed through the Pacific Instruments chassis for amplification and anti-alias filtering. The anti-aliasing filters were set to $400 \mathrm{~Hz}$ for the RVDTs as they were routed only to a digital control system running at a 1,000 $\mathrm{Hz}$ frame rate (dSpace1), and all other signals were filtered at $100 \mathrm{~Hz}$ to be compatible with the other digital control system running at a $200 \mathrm{~Hz}$ frame rate (dSpace2). Servo valve signals were routed to a voltage-to-current converter and back to the model as shown in the figure. Model signals were "teed" and routed to a strip chart for monitoring and to the TDT Data Acquisition System (DAS) for recording. The TDT DAS was set to record data at $500 \mathrm{~Hz}$ with its own anti-aliasing filters set to $200 \mathrm{~Hz}$.

The snubber control system, dSpace1 and dSpace2 internal block diagrams, and the external signals connecting these systems are depicted in figure 9. All signals external to the dSpace blocks are analog, with dSpace input signals being converted from volts to engineering units prior to processing and output signals being converted from engineering units back to volts. For signals intended to depict discrete system states like FlightMode, programming logic was used to decode the meaning of the analog signal.

The hydraulic actuators in the snubbing system were operated by solenoid valves that were controlled using the snubber control system. The heart of the snubber control system was a latching circuit that could be tripped by a manual "chicken switch" or a Snub! command signal from dSpace1. The status of the latching circuit (snubbed or unsnubbed) was communicated back to the dSpace systems by the SNUBXSTAT signal. The PSNUB and ZSNUB signals communicated the state of the plunge brake and pitch snub mechanisms in the model. A detailed description of the snubber control system and associated hydraulic components is described in a separate section, below.

As shown in figure 9, dSpace2 incorporated a flight control block and a set of externally generated control surface commands that could be summed and output as analog control surface command signals to dSpace1. The excitation signal could be added to various combinations of the control surface commands when conducting ParamID testing in TestMode 1. The excitation signal is used internal to the flight control block for TestModes of 2 or greater. The gust load alleviation and trim control laws were implemented within the flight control block. This flight control block included a GUI interface and programming logic for controlling or initiating certain events like resetting the system or initiating a launch. These operator inputs are depicted in the figure. The FlightMode state is communicated from dSpace2 to the WatchDog system as shown.

The servo-control loops and the WatchDog system were implemented on dSpace1. The servo-loops were independent PID control loops equipped with output saturation blocks to prevent overdriving the 


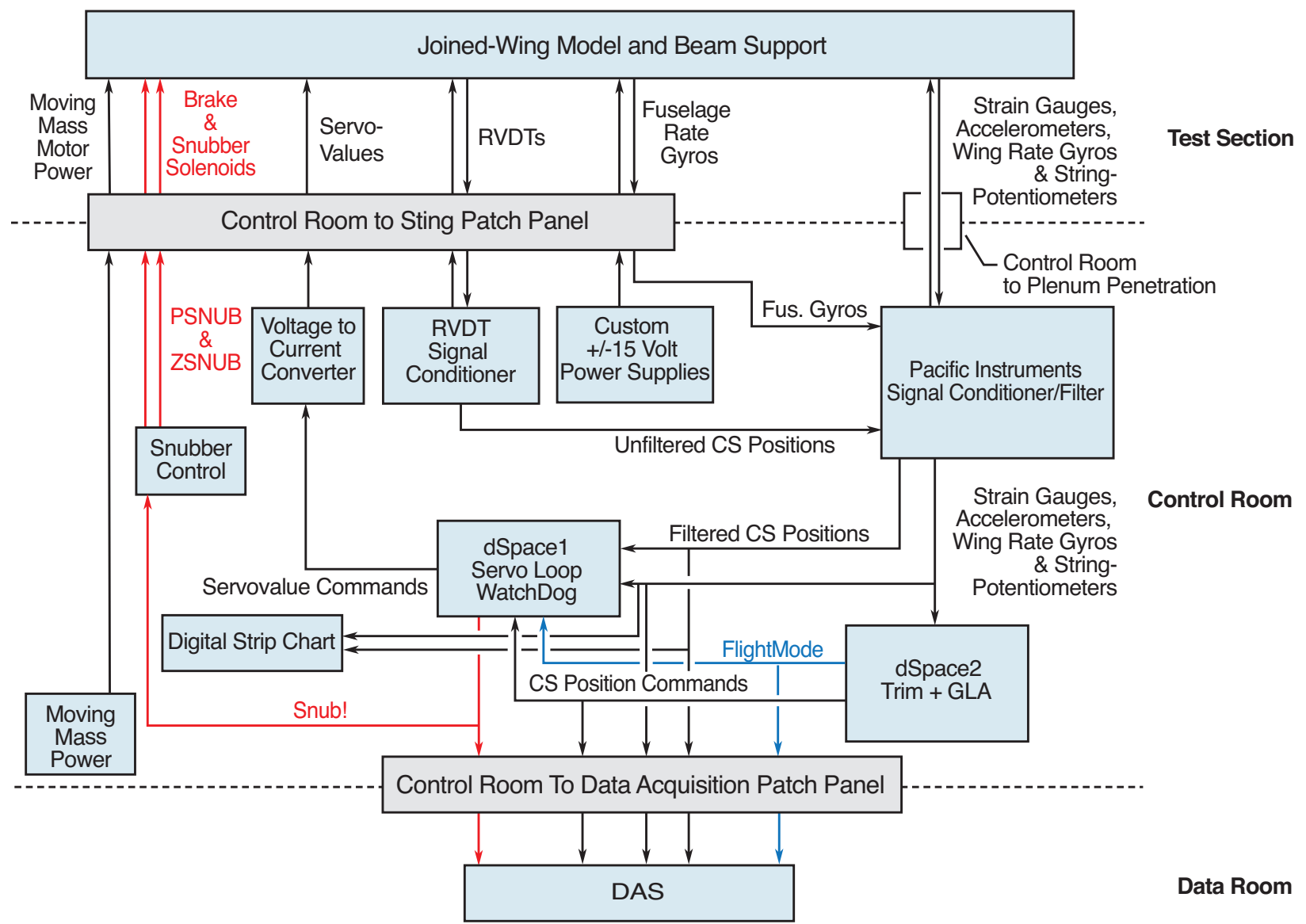

Figure 8. Signal routing used in the joined-wing tests.

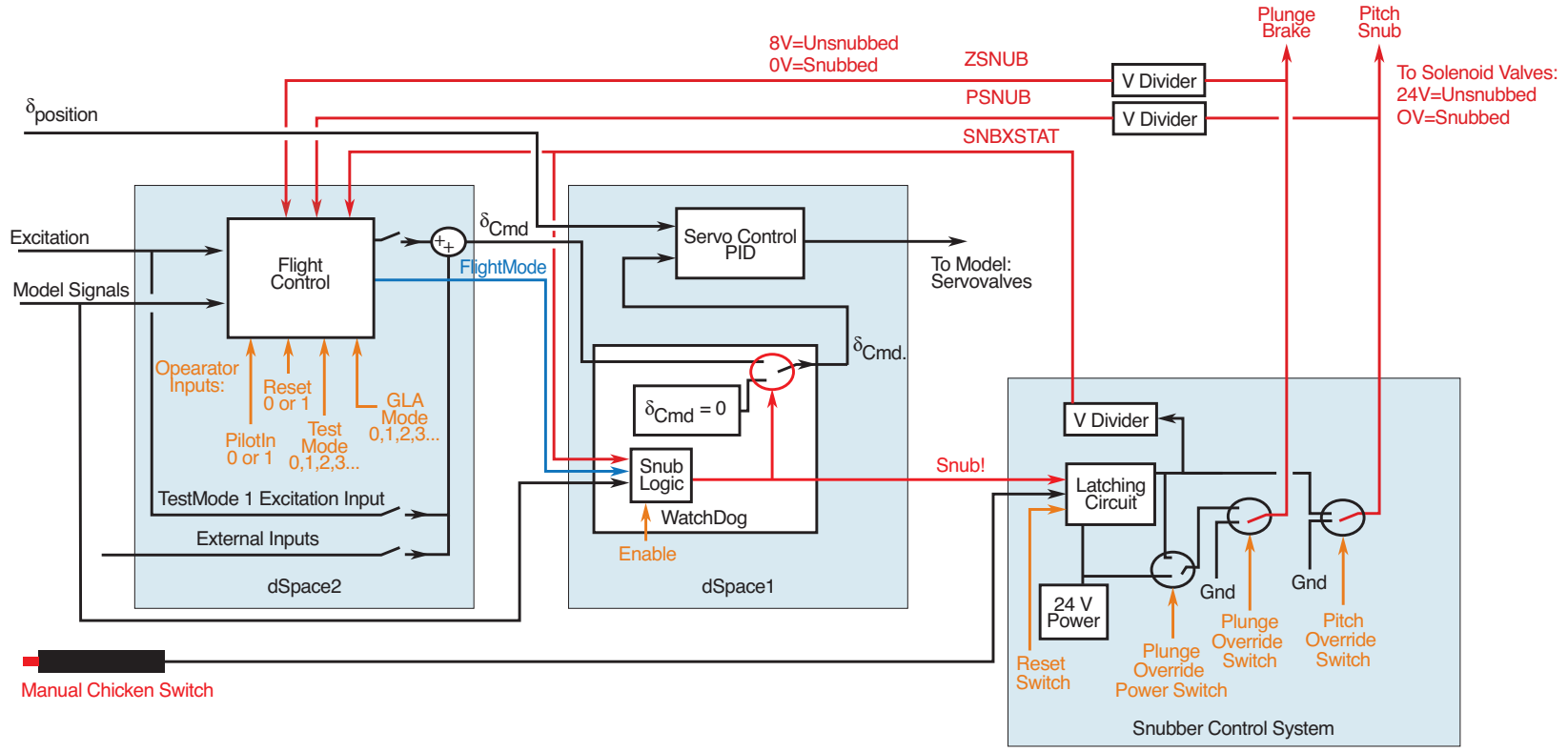

Figure 9. dSpace and snubber control block diagram. 
actuators. The WatchDog system monitored the model signals, and when a fault was detected, it would issue a Snub! command and transfer control to the emergency control law via the switch shown in figure 9. For the joined-wing tests, the emergency controller consisted simply of $0^{\circ}$ control surface commands. In addition to the WatchDog system, the control block on dSpace 2 had a fault detection algorithm and could arrest the model by setting value of FlightMode to 6 .

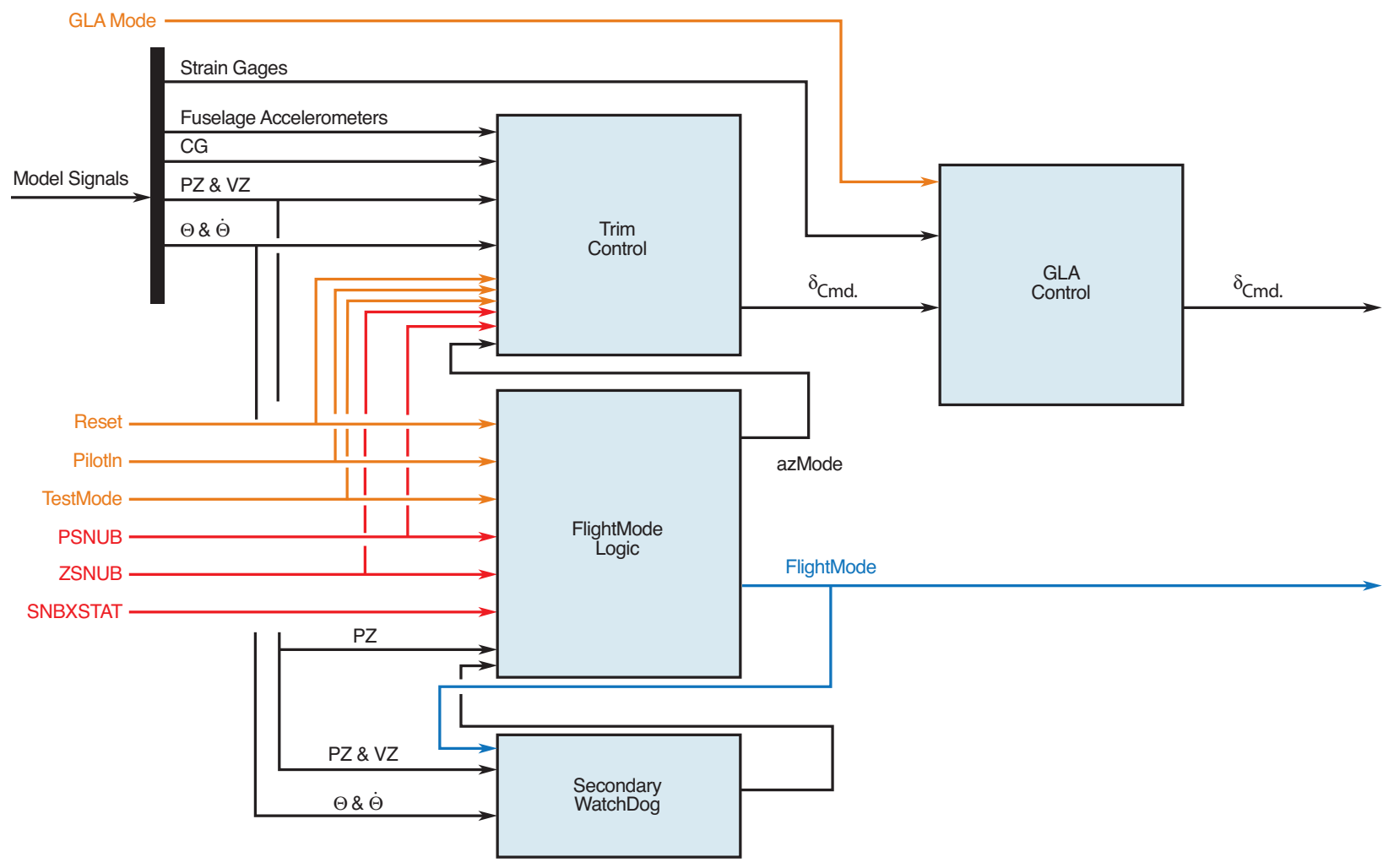

Figure 10. Flight control block diagram.

Key features of the flight control block are shown in figure 10. The primary components of this block are the trim and gust load alleviation blocks, the FlightMode logic block, and the fault detection block. Model signals, snubber related signals, operator inputs, and the relevant model signals are shown. The fault detection algorithm will be discussed in a separate section along with the WatchDog system, but when a fault is detected it is communicated to the FlightMode logic block as shown whereupon the FlightMode parameter is set to 6 . The trim controller has two modes of operation: Theta hold and altitude (Z) hold. The exact mode of operation is determined by the user inputs, the model vertical position, and the azMode parameter. Logic for ramping the vertical position set point from the lower stop to tunnel centerline is also contained in the trim control block. The operation of the GLA control block is controlled by the user input GLAMode. When GLAMode is set to 0, the GLA control block simply passes through the control surface commands. When this parameter is greater than 0 , strain gauge feedback is used to generate GLA control surface commands that are added to the trim controller outputs. It should be pointed out that for simplicity, the excitation signal shown in figure 9 is not shown here. Also not shown is the logic whereby the TestMode parameter can inject the excitation signal at various points in the trim or GLA control blocks. In order to assess controller performance an additional 17 signals were used to record various parameters within the trim control and GLA loops. While also not shown, these signals are routed to and recorded on the DAS.

\section{A. dSPACE Digital Control Systems}

Each dSPACE Digital Control System consists of a rack containing a host computer, a target system, a keyboard, a monitor, BNC patch panels for IO, and an uninterruptible power source. The heart of the DCS is the target system that includes a dSPACE DS1006 control processor board utilizing a 2.6GHz AMD Opteron processor connected to three dSPACE DS2002 multi-channel A/D boards and one dSPACE DS2103 
multi-channel D/A converter board. The A/D boards each have 32 channels utilizing 16 bit quantization with an input range of \pm 10 Volts. The D/A board contains 32 channels of 14 quantization bits designed for \pm 10 Volts and a settling time of $10 \mu \mathrm{sec}$.

The controller software is developed within the MatLab Simulink environment, then compiled and downloaded to the target processor via the dSPACE and MatLab Real-Time Interface. An integral component of the dSPACE tools is the ControlDesk application. ControlDesk provides the user interface to the target processor for the development and implementation of the GUI. The host computer runs the GUI and controls all communications between the processors.

\section{B. Snubber Control System}

The system described in reference 5 was modified to support the joined-wing tests. The original system consisted of the snubber control chassis and an external manifold assembly. It supported only a single solenoid valve located in a manifold assembly external to the model. In addition to the single solenoid valve, the external manifold assembly consisted of an adjustable pressure switch and two regulators for supplying up to two lower hydraulic pressures to the wind-tunnel model. Hydraulic pressure transducers were included to monitor the supply pressure as well as the two regulated pressures. The pressure switch was wired to both an indicator light and an audible alarm housed in the snubber control chassis.

For the joined-wing tests, a second override switch and alternative 24 VDC power (red covered toggle switch) were added to the snubber control chassis. This version of the system is shown in figure 11 . While the previously described manifold assembly was used to monitor and regulate hydraulic pressure to the model, two Parker Hannifin solenoid valves located within the wind-tunnel model were used for model restraint. These valves provided separate control of the pitch snubber mechanism and the brake. Hydraulic fluid, at 1,000 psi, from the TDT 30 gpm pump supplied both the joined-wing actuators and the two solenoid valves. The solenoid valves were normally open and required 24 VDC power to remove pressure from the snubbing system thereby releasing the model.

The snubber control chassis and a handheld chicken switch are shown in figure 11, and key aspects of the snubber control are shown in figure 9. Two amber colored lights on the front of the snubber control box indicate which source initiated the Snub! command, chicken switch or external source (WatchDog system). Resetting of the relays and lights was accomplished with a momentary toggle switch (reset switch). Two independent lighted switches are used to hold a braked/snubbed condition. The plunge override power switch allows the operator to momentarily release the brake to recover (lower) the model after the brake/snubber has been engaged during fight.

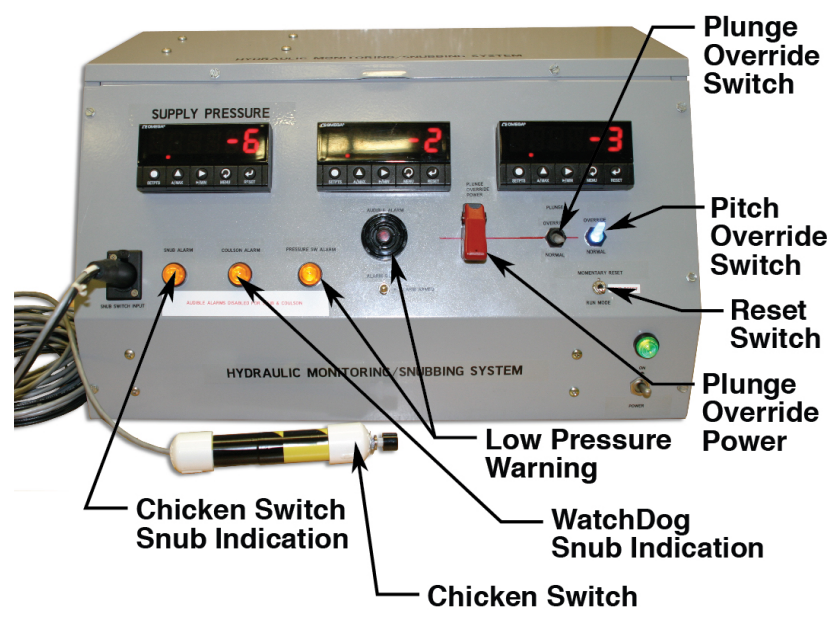

Figure 11. Snubber control chassis containing the snubber control system with manual Snub! (chicken) switch and hydraulic pressure displays. 


\section{RVDT and Servo Valve Signal Conditioning}

The 13 active control surfaces on the joined-wing model exceeded the original signal conditioning capabilities at the TDT. As a result, two custom chassis were fabricated at the TDT using commercially available signal conditioning components.

The RVDT signal conditioner chassis consisted of 16 LDM-1000 LVDT DIN rail mounted signal conditioner modules and their DC power source manufactured by Schaevitz Sensors. These conditioner modules supplied an AC signal to the RVDTs and then demodulated and amplifed the output. A number of internal dip switches can be used to configure the units. For the joined-wing tests the RVDTs were driven at $3 \mathrm{~V}$ RMS, and the position output range was set to $\pm 5 \mathrm{Vdc}$. The setting of the internal filter and excitation frequency will be discussed in a separate section.

The servo valve signal conditioner chassis consisted of $8 \mathrm{VC} 2124$ two axis voltage-to-current converters manufactured by Delta Computer Systems. Each of these units transforms $\pm 10 \mathrm{~V}$ signals into current signals capable of driving the Moog hydraulic servo valves. Each unit can drive two servo valves, and full scale current output is selectable with the $\pm 10 \mathrm{~mA}$ setting used for the joined-wing tests.

\section{TDT Data Acquisition System}

The TDT Open Architecture Data Acquisition System consists of three data acquisition/reduction systems. The Real-Time Systems available to the facility are the Tunnel OADAS (TDTDASE), the Model Preparation Area OADAS (TDTDASD) and The Mobile OADAS (TDTDASM). Together, these computer systems provide the functionality of acquiring, processing, recording and displaying data from the tunnel, the model preparation area, and other locations where a mobile system may be required. These functions are largely identical among all three systems. The Mobile system was used during model preparation and the Tunnel system was using during the three wind-tunnel tests of the joined-wing model.

The tunnel data acquisition subsystem is responsible for collecting the data from several different data acquisition units. The analog-to-digital conversions are provided by four NEFF 600 data acquisition units (DAUs). Each DAU can scan up to 64 analog channels at an aggregate rate almost 100,000 samples per second. In addition to the analog channels, the first DAU also contains digital channels for tunnel parameter and time code data.

\section{WatchDog and Fault Detection Systems}

Due to the high risk associated with aeroelastic wind-tunnel testing, a variety of manual and automated safety systems have been used in the TDT. The manually operated tunnel bypass valves are generally the first line of defense for flutter testing as they can rapidly reduce test section dynamic pressure and Mach number. Depending on the type of model and mount system employed, model stabilization or arrestment mechanisms have also been considered. Previously employed model stabilization devices have included decoupler pylons that change model dynamics to a more benign configuration and model arrestment devices including pneumatic snubber cables for cable mounted models. ${ }^{17}$ Manual engagement of these devices has at times been supplemented by automated systems. Such systems have previously been employed only for non-flying models with the tunnel bypass valves and/or decoupler devices being triggered based on threshold exceedances. ${ }^{20}$

The range of rigid body motion and the potential for high speed impact afforded by the new mount system made the AEI free-flying tests among the riskier tests conducted in the TDT. The snubber mechanism was intended to reduce risk to the model and facility, and could be triggered manually. In the tunnel testing environment, the test engineer must in essence perform system ID in real-time to determine whether a behavior is a benign oscillation or a potentially fatal divergence. Mix in a little hope, and the reaction time can be significant. The WatchDog system was developed to keep the model and mount system from exceeding structural safety limits by monitoring signals from the wing and mount system.

The WatchDog was implemented on dSpace1 as shown in figure 9. The key features of the WatchDog system are the emergency control law and the snub logic. The snub logic monitors the model signals and issues a Snub! command when a fault is detected. Issuing the Snub! command engages the brake and pitch snubber and switches the control of model control surfaces from dSpace2 to the emergency control law as shown in the figure. The system was originally developed for the flying-wing tests ${ }^{5}$ and was modified for use here. As previously mentioned, the emergency controller used on the joined-wing tests consisted of simply 


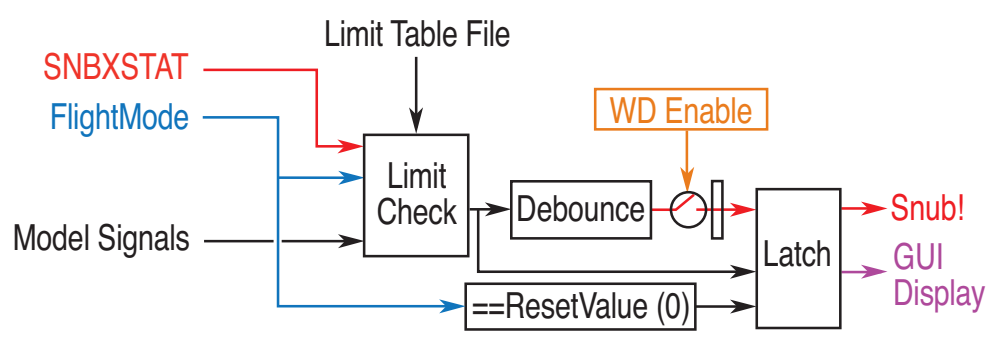

Figure 12. WatchDog system snub logic block diagram.

commanding the control surfaces to $0^{\circ}$.

A block diagram of the WatchDog snub logic is shown in figure 12. The system's primary function was to monitor a select set of model signals and issue the Snub! command when parameter limits were exceeded. In addition to the model signals exceeding limits, the Snub! command would be issued if a FlightMode value of 6 was detected. The FlightMode values were designed to facilitate launch and recovery, incremental testing, stability margin data collection and GLA testing. Based on the specific value of FlghtMode, different sets of WatchDog limits could be used for reset, takeoff, flight, or GLA testing. For instance, when the FlightMode associated with model launch and climb-out was used, the lower model position limits needed to be ignored until the model cleared a certain height ( $\mathrm{PZ}$ value). The FlightMode designations and integer values used in the JWS tests are listed in table 1. As indicated previously, the FlightMode parameter was not a direct user input. The FlightMode logic block in figure 10 determined the appropriate value based on user inputs and the vertical position of the model. Additional details will be covered in the model launch, test, and recovery procedures section of the paper.

The selected signals and FlightMode dependent limits were compared in the limit check block in figure 12 . Detected faults were passed to the debounce block where 3 consecutive frames of any particular signal fault were required to issue the WatchDog Snub! command. The debounce prevented a single frame noise event from issuing a false alarm. A latch was used to quickly diagnose the cause of WatchDog commanded Snub! events. The parameter that caused the trip would be held and displayed to the user via the GUI on dSpace1. The WatchDog latch was reset by setting the FlightMode to zero.

Preliminary modeling and review of previous tests allowed for initial values of the WatchDog limits to be set. As the wind-tunnel test progressed, some limits were expanded based on operational experience. For example, as lower frequency gusts were tested, vertical velocity and pitch rate became large, exceeding initial WatchDog limits, but since model response remained stable and bounded, the WatchDog limits were expanded to permit testing. During testing, the limit values could be modified directly in the real time processor memory from the dSpace1 user interface. These modifications were then recorded back into MatLab script files for future use. Table 1 defines the various FlightMode limits and lists the monitored parameters along with the final (end of Test 614) set of limits. As can be seen from the table a total of 22 model signals were monitored directly: 12 wing control surfaces, 1 rudder, 4 rigid body measurements, and 5 strain gauges. In addition three ad hoc or combined parameters were monitored. These parameters were an attempt to improve safety by applying some engineering judgement. For instance, if the model had negative vertical position (below tunnel centerline) and positive vertical velocity (moving up), that combination would be acceptable. Alternatively, the combination of negative position and negative velocity would be cause for concern. Thus, multiplying vertical position $(\mathrm{PZ})$ and vertical velocity $(\mathrm{VZ})$ produced a parameter that was acceptable when negative and given a safe upper limit and monitored by the WatchDog. Similar logic was used to construct a parameter consisting of $\Theta$ and PZ. 
Table 1. FlightModes, WatchDog parameters, and parameter limits. Limits are in units of degrees, inches, micro-strain, and seconds.

\begin{tabular}{cccccccccccccc}
\hline \hline FlightMode & Reset & \multicolumn{2}{c}{ Taxi 1} & \multicolumn{2}{c}{ Taxi 2} & \multicolumn{2}{c}{ Transition } & \multicolumn{2}{c}{ Fly 1} & \multicolumn{3}{c}{ Fly 2} & \multicolumn{2}{c}{ Snub } \\
& 0 & \multicolumn{2}{c}{1} & \multicolumn{2}{c}{2} & \multicolumn{2}{c}{3} & & 4 & & 5 & 6 \\
\hline Parameter & & Min & Max & Min & Max & Min & Max & Min & Max & Min & Max \\
$\delta_{\text {Rudder }}$ & $\pm \infty$ & -10 & 10 & -10 & 10 & -10 & 10 & -10 & 10 & -10 & 10 & $\pm \infty$ \\
$\delta_{C S}$ & $\pm \infty$ & -13.5 & 13.5 & -13.5 & 13.5 & -13.5 & 13.5 & -13.5 & 13.5 & -13.5 & 13.5 & $\pm \infty$ \\
$V Z \times P Z$ & $\pm \infty$ & -150 & 50 & -150 & 150 & -350 & 350 & -400 & 200 & -400 & 250 & $\pm \infty$ \\
$V Z^{2} \times P Z$ & $\pm \infty$ & -2000 & 1600 & -2000 & 1600 & -2000 & 1600 & -2000 & 1600 & -8000 & 8000 & $\pm \infty$ \\
$\left(\Theta-1^{\circ}\right) P Z$ & $\pm \infty$ & -40 & 40 & -40 & 40 & -40 & 20 & -40 & 20 & -40 & 25 & $\pm \infty$ \\
VZ & $\pm \infty$ & -20 & 20 & -20 & 20 & -20 & 20 & -20 & 20 & -40 & 40 & $\pm \infty$ \\
PZ & $\pm \infty$ & -22 & -18.5 & -22 & -18.5 & -22 & 0 & -16 & 16 & -16 & 16 & $\pm \infty$ \\
$\Theta$ & $\pm \infty$ & -1 & 3 & -1 & 3 & -0.5 & 3 & 0 & 3 & 0 & 3.25 & $\pm \infty$ \\
$\dot{\Theta}$ & $\pm \infty$ & -15 & 15 & -15 & 15 & -15 & 15 & -15 & 15 & -30 & 30 & $\pm \infty$ \\
$S G F W L I$ & $\pm \infty$ & -150 & 150 & -150 & 150 & -150 & 150 & -150 & 150 & -150 & 150 & $\pm \infty$ \\
$S G F W R I$ & $\pm \infty$ & -150 & 150 & -150 & 150 & -150 & 150 & -150 & 150 & -150 & 150 & $\pm \infty$ \\
$S G T F$ & $\pm \infty$ & -450 & 450 & -450 & 450 & -450 & 450 & -450 & 450 & -450 & 450 & $\pm \infty$ \\
$S G T M$ & $\pm \infty$ & -200 & 200 & -200 & 200 & -200 & 200 & -200 & 200 & -200 & 200 & $\pm \infty$ \\
$S G T A$ & $\pm \infty$ & -150 & 150 & -150 & 150 & -150 & 150 & -150 & 150 & -150 & 150 & $\pm \infty$ \\
\hline
\end{tabular}


An additional fault detection system was implemented along with the control laws on dSpace2 to provide an alternative method of detecting an unstable or runaway condition. This system monitored a combination of the vertical position and velocity, and a combination of the pitch angle and rate. The limits used were controlled by the state of the FlightMode parameter. The position and velocity terms were scaled by the limits so that \pm 1 indicated that the particular degree of freedom was at its limit. The scaled terms were squared and added to form circular error terms as shown in equations 1 and 2. If the circular error term exceeded 1, the FlightMode was set to the Snub! value of 6 . When this was detected by the primary WatchDog the Snub! signal was sent to Snubber Control System and the model brake and pitch snubber were activated. The values of the FlightMode dependent terms are listed in table 2.

$$
\begin{gathered}
\left(\frac{P Z-P Z_{\text {Center }}}{P Z_{\text {Range }}}\right)^{2}+\left(\frac{V Z}{V Z_{\text {Limit }}}\right)^{2} \leq 1.0 \\
\left(\frac{\Theta-\Theta_{\text {Center }}}{\Theta_{\text {Range }}}\right)^{2}+\left(\frac{\dot{\Theta}}{\dot{\Theta}_{\text {Limit }}}\right)^{2} \leq 1.0
\end{gathered}
$$

Table 2. Fault detection system parameters. Values are in units of degrees, inches, and seconds. Values in parenthesis were initial values.

\begin{tabular}{cccccccc}
\hline \hline FlightMode & Reset & Taxi 1 & Taxi 2 & Transition & Fly 1 & Fly 2 & Snub! \\
& 0 & 1 & 2 & 3 & 4 & 5 & 6 \\
\hline Parameter & & & & & & & \\
$\Theta_{\text {Center }}$ & 0.5 & 0.5 & 0.0 & 0.9 & 0.9 & 0.9 & 0.5 \\
$\Theta_{\text {Range }}$ & 2.0 & 2.0 & 3.0 & 2.0 & $2.0(0.5)$ & $3.5(2.5)$ & 2.0 \\
$\dot{\Theta}_{\text {Limit }}$ & 15.0 & 15.0 & 15.0 & $15.0(5.0)$ & $15.0(5.0)$ & 50.0 & 15.0 \\
$P Z_{\text {Center }}$ & -21.6 & -21.6 & -21.6 & -8.4 & 0.0 & 0.0 & -21.6 \\
$P Z_{\text {Range }}$ & 4.2 & 4.2 & 4.2 & 12.0 & $12.0(8.0)$ & 18.0 & 4.2 \\
$V Z_{\text {Limit }}$ & 18.0 & 18.0 & 24.0 & 30.0 & 18.0 & 60.0 & 18.0 \\
\hline
\end{tabular}

\section{Model Launch, Test, and Recovery}

This section will describe how the joined-wing model was launched, tested, and recovered. The nominal procedures are shown in figure 13. What is depicted is a notional sequence where the dynamic pressure is ramped up to $51 \mathrm{psf}$, tests are performed, the model is secured, and dynamic pressure is returned to zero. The status of the snubber control system, the dSpace2 control system, and the vertical position of the model (PZ) are shown. When parameters change they are depicted in red. The yellow highlighted changes require manual inputs while the others are automatic. Starting at the top, five groupings of events are shown in figure 13. These sequence groupings will be described next.

Reset and PSNUB Release. Start with model snubbed. Tunnel dynamic pressure is set to 51 psf, the relays (SNBXSTAT) and flight controller are reset, and the pitch snubber (PSNUB) is released. At this point dSpace2 engages the THETA control loop which tracks a $\Theta$ set point value. Generally, the set point was around $0.5^{\circ}$.

Theta Loop ParamID Testing. The operator sets TestMode to a value greater than 0. Depending on the value of TestMode, excitation signals are added to various signals within the Theta control loop and ParamID data are acquired. When ParamID data acquisition is complete, TestMode is set back to zero. This set of sequences was used early in the test program, but it was generally skipped.

Launch. The operator changes the PilotIn parameter from 0 to 1 and then releases the brake (ZSNUB). The control system engages the $\mathrm{Z}$ control loop and ramps up the $\mathrm{PZ}$ set point to a centerline value of 0 . Along the way, FlightMode changes automatically as the model passes through certain PZ thresholds. 


\begin{tabular}{|c|c|c|c|c|c|c|c|c|c|c|c|c|c|}
\hline $\begin{array}{c}\text { Test } \\
\text { Group }\end{array}$ & $\mathbf{Q}$ & $\begin{array}{r}\text { Snub/ } \\
\text { SNBXSTA }\end{array}$ & $\begin{array}{l}\text { rake Cor } \\
\text { PSNUB }\end{array}$ & trol & PilotIn & Trim CL & $\begin{array}{l}\text { dSpace Contr } \\
\text { FlightMode }\end{array}$ & $\begin{array}{l}\text { rols/St } \\
\text { Reset }\end{array}$ & $\begin{array}{l}\text { ates } \\
\text { TestMode }\end{array}$ & GLAMode & CG & PZ & Notes \\
\hline \multirow{5}{*}{$\begin{array}{l}\text { Reset \& } \\
\text { PSNUB } \\
\text { Release }\end{array}$} & 0 & TRIP & SNUB & ON & 0 & OPEN & 6 & 0 & 0 & 0 & $5 \%$ & $<$ ZLT & Model Secure, Tunnel Off \\
\hline & 51 & TRIP & SNUB & ON & 0 & OPEN & 6 & 0 & 0 & 0 & $5 \%$ & $<\mathrm{ZLT}$ & Tunnel Conditions Set \\
\hline & 51 & RESET & SNUB & ON & 0 & OPEN & 0 & 1 & 0 & 0 & $5 \%$ & $<\mathrm{ZLT}$ & Reset Systems \\
\hline & 51 & RESET & SNUB & ON & 0 & OPEN & 1 & 0 & 0 & 0 & $5 \%$ & $<\mathrm{ZLT}$ & \\
\hline & 51 & RESET & FREE & ON & 0 & THETA & 1 & 0 & 0 & 0 & $5 \%$ & $<\mathrm{ZLT}$ & Release Pitch Snubber \\
\hline \multirow{3}{*}{$\begin{array}{c}\text { Theta Loop } \\
\text { ParamID } \\
\text { Testing }\end{array}$} & 51 & RESET & FREE & ON & 0 & THETA & 2 & 0 & $>0$ & 0 & $5 \%$ & $<\mathrm{ZLT}$ & Engage ParamID Testing Mode \\
\hline & 51 & RESET & FREE & ON & 0 & THETA & 2 & 0 & $>0$ & 0 & $5 \%$ & $<\mathrm{ZLT}$ & Acquire ParamID Data \\
\hline & 51 & RESET & FREE & ON & 0 & THETA & 1 & 0 & 0 & 0 & $5 \%$ & $<\mathrm{ZLT}$ & Disengage from ParamID Testing Mode \\
\hline \multirow{4}{*}{ Launch } & 51 & RESET & FREE & ON & 1 & THETA & 1 & 0 & 0 & 0 & $5 \%$ & $<\mathrm{ZLT}$ & \\
\hline & 51 & RESET & FREE & FREE & 1 & z & 1 & 0 & 0 & 0 & $5 \%$ & $<\mathrm{ZLT}$ & PZ Setpoint Starts Ramp to O" \\
\hline & 51 & RESET & FREE & FREE & 1 & z & 3 & 0 & 0 & 0 & $5 \%$ & $>$ ZLT & PZ Based Transition \\
\hline & 51 & RESET & FREE & FREE & 1 & z & 4 & 0 & 0 & 0 & $5 \%$ & $>\mathrm{ZFT}$ & PZ Based Transition \\
\hline \multirow{5}{*}{$\begin{array}{c}\text { Free Flying } \\
\text { ParamID } \\
\text { and/or GLA } \\
\text { Testing }\end{array}$} & 51 & RESET & FREE & FREE & 1 & z & 5 & 0 & 0 & 0 & $5,0,-5,-10 \%$ & $\sim 0.0^{\prime}$ & Adjust CG to Provide Desired Stability \\
\hline & 51 & RESET & FREE & FREE & 1 & z & 5 & 0 & $\geq 0$ & 0 & $5,0,-5,-10 \%$ & $\sim 0.0^{\prime}$ & Engage ParamID Testing Mode \\
\hline & 51 & RESET & FREE & FREE & 1 & z & 5 & 0 & $\geq 0$ & $\geq 0$ & $5,0,-5,-10 \%$ & $\sim 0.0^{\prime}$ & Select GLA Control Law \\
\hline & 51 & RESET & FREE & FREE & 1 & z & 5 & 0 & $\geq 0$ & $\geq 0$ & $5,0,-5,-10 \%$ & $\sim 0.0^{\prime}$ & Acquire ParamID/GLA Data \\
\hline & 51 & RESET & FREE & FREE & 1 & z & 4 & 0 & 0 & 0 & $5,0,-5,-10 \%$ & $\sim 0.0^{\prime}$ & Disengage from Test/GLA Modes \\
\hline \multirow{7}{*}{$\begin{array}{l}\text { Land Model } \\
\text { and Secure }\end{array}$} & 51 & RESET & FREE & FREE & 1 & z & 4 & 0 & 0 & 0 & $5 \%$ & $\sim 0.0^{\prime}$ & Set CG to $5 \%$ Static Margin \\
\hline & 51 & RESET & FREE & FREE & 0 & z & 4 & 0 & 0 & 0 & $5 \%$ & $\sim 0.0^{\prime}$ & PZ Setpoint Starts Ramping Down \\
\hline & 51 & RESET & FREE & FREE & 0 & z & 3 & 0 & 0 & 0 & $5 \%$ & $<\mathrm{ZFT}$ & PZ Based Transition \\
\hline & 51 & RESET & FREE & FREE & 0 & THETA & 1 & 0 & 0 & 0 & $5 \%$ & $<$ ZLT & PZ Based Transition \\
\hline & 51 & TRIP & FREE & FREE & 0 & OPEN & 6 & 0 & 0 & 0 & $5 \%$ & $<\mathrm{ZLT}$ & Engage Brake and Pitch Snubber \\
\hline & 51 & TRIP & SNUB & ON & 0 & OPEN & 6 & 0 & 0 & 0 & $5 \%$ & $<\mathrm{ZLT}$ & Engage Overide Switches \\
\hline & 0 & TRIP & SNUB & ON & 0 & OPEN & 6 & 0 & 0 & 0 & $5 \%$ & $<\mathrm{ZLT}$ & \\
\hline \multicolumn{5}{|c|}{ ZLT=Z-Landing-Threshold: $P Z=-18.25 "$} & $\mathrm{ZFT}=\mathrm{Z}$ & $y$-Thresh & hold: $P Z=-6.0^{\prime \prime}$ & Tur & I Center L & : $P Z=0.0^{\prime \prime}$ & $\operatorname{Rec}$ & $\mathrm{c} C \mathrm{Ch}$ & Red $=$ Manual Change \\
\hline
\end{tabular}

Figure 13. Description of the launch and test procedures used with the JWS model.

Free Flying ParamID and/or GLA Testing. Using the moving mass system, the CG is remotely adjusted to provide the desired static margin. The operator selects a TestMode value to determine the type of ParamID testing to be conducted, and selects the GLAMode to determine which, if any, GLA control law is to be tested. When ParamID and/or GLA testing is complete, TestMode and GLAMode are returned to 0 .

Land Model and Secure. The CG is remotely adjusted to the full forward position providing $+5 \%$ static margin. The operator then sets PilotIn to 0 telling the controller to land the model. The PZ set point is ramped down. At certain PZ thresholds, FlightMode transitions to 3, then to 1 where the Z control loop is disengaged. Finally, the operator trips the snubber relays (SNBXSTAT) and engages the override switches (PSNUB and ZSNUB) to secure the model.

An example set of data acquired during model launch is shown in figure 14. The upper plot shows time histories of PZ, $\Theta$, and aft wing control surface commands. The lower plot shows the three snubber related values along with FlightMode. Snubber values of $0 \mathrm{~V}$ indicate a snubbed or tripped state while a value of approximately $8 \mathrm{~V}$ indicates an unsnubbed or reset condition. The launch procedure described above and in figure 13 is followed except that ParamID testing is not shown and the time histories end once the model has achieved flight.

It should be pointed out that the nominal sequence shown in figure 13 was almost never followed exactly. Typically, the WatchDog system would arrest the model during ParamID or GLA testing. When this happened the pitch snub (PSNUB) and brake (ZSNUB) override switches were set to the snubbed/brake-on positions and tunnel dynamic pressure was reduced to about $42 \mathrm{PSF}$. The plunge override power switch and the plunge override switch were then used to momentarily release the brake to allow the model to settle to the bottom stop. At that point, tunnel dynamic pressure would be returned to $51 \mathrm{PSF}$ and the sequence in figure 13 would resume from the top.

\section{Trim Controller Architecture}

The trim controller was designed to launch, fly and land the model in the wind tunnel and to serve as the reference for GLA performance. The trim controller consisted of two main elements, a vertical (Z) feedback loop and a pitch $(\Theta)$ feedback loop. The vertical loop consisted of a simple PID controller that generated an acceleration command. The pitch loop consisted of a PID plus acceleration feed-forward controller to generate a control surface command from the acceleration command. These two loops used gains that were 


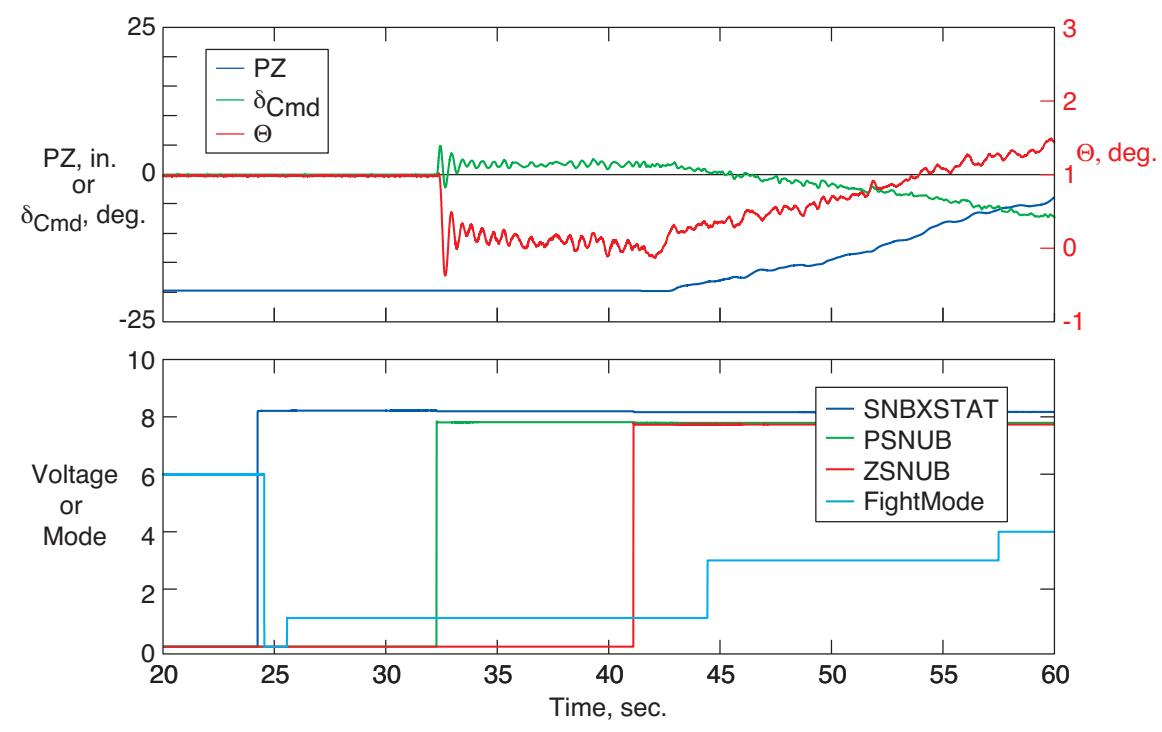

Figure 14. Data acquired during model launch. Test 614 Point $1655 . \delta_{C m d}$ is command signal sent to all aft wing control surfaces.

scheduled based on CG. The single control surface command was passed through a third-order low pass filter to attenuate the response at higher frequencies. The initial set of gains was determined using an analytically derived aeroservoelastic model.

A diagram of the trim controller is shown in figure 15. As indicated, the trim controller has two modes of operation controlled by the azMode parameter: Pitch control only or Altitude (vertical position) control. The routing of excitation signal to the control surface command that is used in TestMode 3 is also shown. The excitation signal along with the unaugmented control surface command were routed to the DAS for near real time assessment of controller stability. Other test modes add the excitation to other signals within the trim control block diagram or the flight control block (figure 10). For clarity the details on these additional test modes and the associated signals that were also routed to the DAS are not shown. The single control surface command signal shown in figure 15 was sent to all six aft wing control surfaces.

\section{TDT Test 613: Free-Flying Function Check and ParamID}

The primary objectives of the first free-flying test of the joined-wing model were to (1) assess the functionality of the model mated to the carriage and beam structure, (2) demonstrate and verify the model launch, test, and recovery procedures, and (3) acquire parameter identification (ParamID) data. The nominal test matrix used for Test 613 is shown in figure 16. As indicated, the model could be tested in one of three different boundary conditions: restrained (pitch snubber and brake engaged), free-in-pitch (brake engaged), and flying. The data acquired in the restrained and free-in-pitch configurations was used largely for system evaluation in preparation for flying the model. The free-flying data was the highest priority, with the majority of data acquired in this configuration.

Most of the data acquired in Test 613 used GLAMode 0, in which only the basic trim control law was used. GLAMode values of 1 and greater denote the use of various GLA control laws. TestMode refers to the type of ParamID testing performed. TestMode 1 was used with the AOS and control surface excitation signals. TestMode values greater than 1 indicated that the excitation signal was being injected at some point within the flight control system. Most of the data acquired during Test 613 consisted of linear sine sweeps as shown in figure 16. In general, the amplitudes of excitation were maximized based on trial and error. In each case, the goal was to obtain the maximum model response without exceeding WatchDog limits. The amplitude of the AOS vanes was fixed at their maximum value of $12^{\circ}$ peak-to-peak. The typical values of control surface excitation are shown, but sometimes larger or smaller amplitudes were used. Specific amplitudes for TestModes of 2 through 11 are not listed because they varied greatly depending on CG 


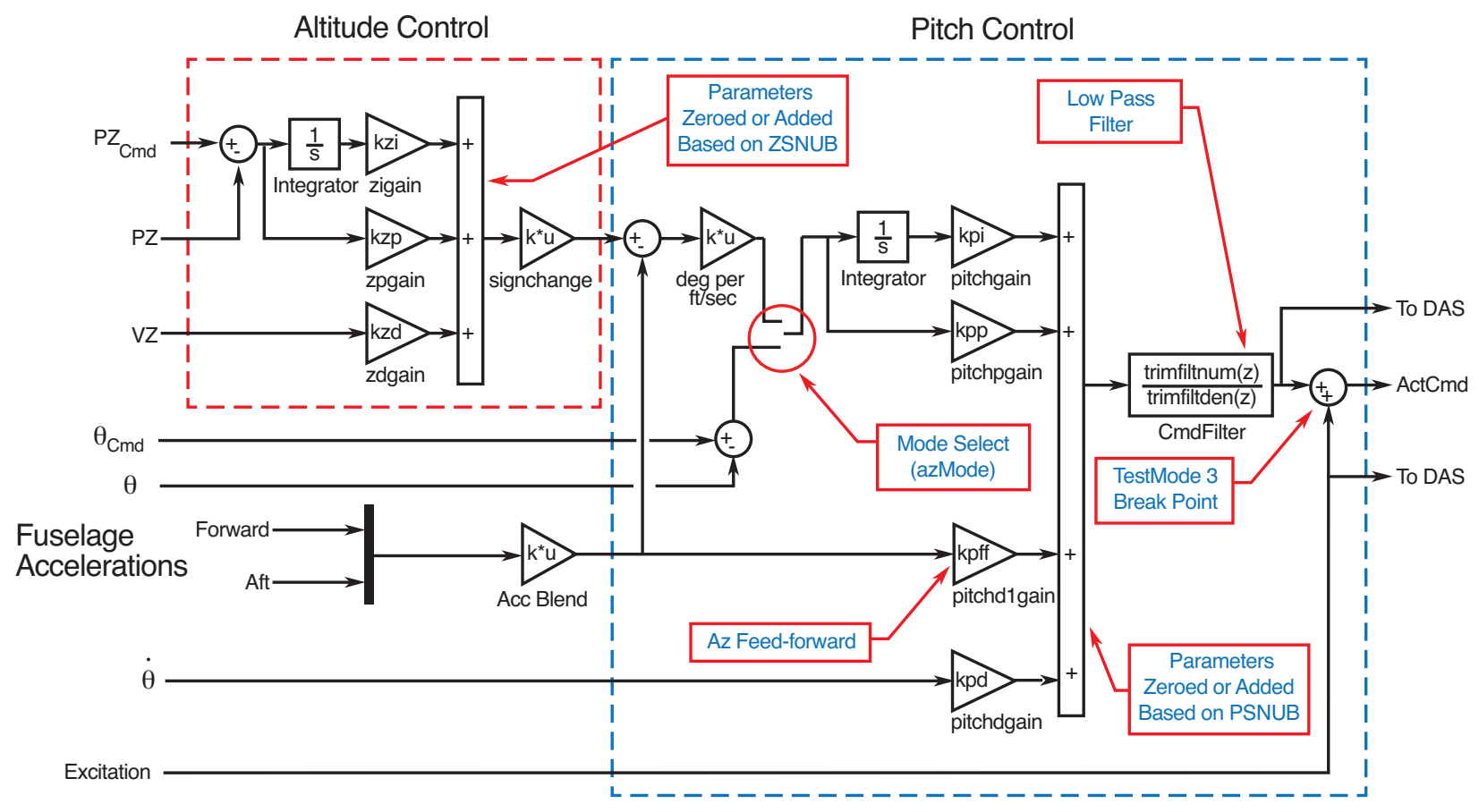

Figure 15. Trim control law diagram.

location and other parameters. The block of data on the right-hand side of figure 16 was repeated for each moving mass location or static margin value. Acquiring data at all the combinations of parameters indicated in the test matrix was in fact not done. Model configurations and data types were prioritized. Some sample wind-tunnel data will be shown in the Test 614 section of the paper.

An analytical ASE model was developed for use in determining the trim controller gains. The initial modeling was based purely on analysis updated with static aerodynamic terms determined from the JWS balance test, TDT Test 606. This ASE model along with the previously described flight control block, support system dynamics, and a model for the AOS-generated gust input were part of a Simulink model. This model is described in more detail in reference 12. This model was used to develop the initial gains for the trim controller. With those gains, the controller was determined to be stabilizing at all model configurations (CG locations). The original gains were designed with $9 \mathrm{db}$ of gain margin and $45^{\circ}$ of phase margin. The actual margins obtained from testing were lower than the predicted margins. Data acquired using TestMode 3 were used to estimate margins of $6 \mathrm{db}$ and $18^{\circ}$ at the $-10 \%$ static stability condition. Figure 17 shows the Nichols plot for $+5 \%$ and $-10 \%$ static stability from both the simulation model and test data.

There were several false starts in developing the best approach to using the wind-tunnel data to refine the ASE model. The technique that was ultimately used involved the use of an optimizer to tune the simulation model to match the test data. This method used nine sets of actuator sweep time histories (six sets of symmetric actuator pairs, all forward actuators, all aft actuators and all forward and aft surfaces) and one set of gust sweep time histories. These data were acquired using TestMode 1 with the model flying via the trim controller. The optimization technique required a large amount of memory and processor time to complete. A typical solution for one CG condition would take approximately 4 CPU days. The solutions obtained from this method produced models with generally very good agreement with the stability margins produced from test data and an accurate match of the first symmetric structural mode. The final linear model contained 18 modes and accurately reproduced the measurements required for the trim and GLA controllers.

\section{TDT Test 614: Free Flight Testing - ParamID and GLA}

The primary objective of the second free-flying joined-wing test was to demonstrate gust load alleviation (GLA). Based on the lessons learned and a review of the data acquired in Test 613, the nominal test matrix 


\begin{tabular}{|c|c|c|c|c|c|c|c|c|c|c|}
\hline & \multicolumn{3}{|c|}{ Boundary Condition } & & & & & & & \\
\hline & \multirow{3}{*}{ 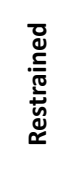 } & \multirow{3}{*}{ 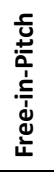 } & \multirow{3}{*}{ 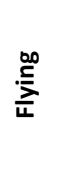 } & & & & \multicolumn{4}{|c|}{ Static Margin $=+5,0,-5, \&-10 \%$} \\
\hline & & & & & \multicolumn{2}{|c|}{ Sweep } & \multicolumn{2}{|c|}{ Symmetric } & \multicolumn{2}{|c|}{ Antisymmetric } \\
\hline & & & & GLA Mode & Linear & Log & Frequency, $\mathrm{Hz}$ & Amplitude & Frequency, $\mathrm{Hz}$ & Amplitude \\
\hline \multicolumn{11}{|l|}{ TestMode1: } \\
\hline Tunnel Turbulence & $x$ & $\mathrm{x}$ & $\mathrm{x}$ & 0 & & & & & & \\
\hline AOS Gust & & & $\mathrm{x}$ & 0 & & & Dwells & $6^{\circ}$ & & \\
\hline AOS Gust & $\mathrm{x}$ & $\mathrm{x}$ & $\mathrm{x}$ & 0 & $60 \mathrm{~s}$ & & $0.1-12$ & $6^{\circ}$ & & \\
\hline FWO Actuator & $x$ & $\mathrm{x}$ & $\mathrm{x}$ & 0 & $60 \mathrm{~s}$ & & $0.1-20$ & $4^{\circ}$ & & \\
\hline FWM Actuator & $x$ & $\mathrm{x}$ & $\mathrm{x}$ & 0 & $60 \mathrm{~s}$ & & $0.1-20$ & $4^{\circ}$ & & \\
\hline FWI Actuator & $x$ & $x$ & $\mathrm{x}$ & 0 & $60 \mathrm{~s}$ & & $0.1-20$ & $4^{\circ}$ & & \\
\hline FW All Actuator & $x$ & $x$ & $\mathrm{x}$ & 0 & $60 \mathrm{~s}$ & & $0.1-20$ & $2.5^{\circ}$ & & \\
\hline AWO Actuator & $x$ & $x$ & $\mathrm{x}$ & 0 & $60 s$ & & $0.1-20$ & $4^{\circ}$ & & \\
\hline AWM Actuator & $x$ & $x$ & $\mathrm{x}$ & 0 & $60 \mathrm{~s}$ & & $0.1-20$ & $4^{\circ}$ & & \\
\hline AWI Actuator & $x$ & $\mathrm{x}$ & $\mathrm{x}$ & 0 & $60 \mathrm{~s}$ & & $0.1-20$ & $4^{\circ}$ & & \\
\hline AW All Actuator & $x$ & $\mathrm{x}$ & $\mathrm{x}$ & 0 & $60 \mathrm{~s}$ & & $0.1-20$ & $2.5^{\circ}$ & & \\
\hline All Actuator & $\mathrm{x}$ & $\mathrm{x}$ & $\mathrm{x}$ & 0 & $60 \mathrm{~s}$ & & $0.1-20$ & $2.5^{\circ}$ & & \\
\hline TestMode 2 & & & $\mathrm{x}$ & 0 & $60 \mathrm{~s}$ & & $0.1-20,0.1-4$ & maximized & & \\
\hline TestMode 3 & & $x$ & $\mathrm{x}$ & 0 & $60 \mathrm{~s}$ & & $0.1-20,0.1-4$ & maximized & & \\
\hline TestMode 4 & & & $\mathrm{x}$ & 0 & $60 \mathrm{~s}$ & & $0.1-20,0.1-4$ & maximized & & \\
\hline TestMode 5 & & & $\mathrm{x}$ & 0 & $60 \mathrm{~s}$ & & $0.1-20,0.1-4$ & maximized & & \\
\hline TestMode 6 & & & $\mathrm{x}$ & 0 & $60 \mathrm{~s}$ & & $0.1-20,0.1-4$ & maximized & & \\
\hline TestMode 7 & & & $\mathrm{x}$ & 0 & $60 \mathrm{~s}$ & & $0.1-20,0.1-4$ & maximized & & \\
\hline TestMode 8 & & $\mathrm{x}$ & & 0 & $60 \mathrm{~s}$ & & $0.1-20,0.1-4$ & maximized & & \\
\hline TestMode 9 & & & $\mathrm{x}$ & 0 & $60 \mathrm{~s}$ & & $0.1-20,0.1-4$ & maximized & & \\
\hline TestMode 10 & & & $\mathrm{x}$ & 0 & $60 \mathrm{~s}$ & & $0.1-20,0.1-4$ & maximized & & \\
\hline TestMode 11 & & $x$ & & 0 & $60 \mathrm{~s}$ & & $0.1-20,0.1-4$ & maximized & & \\
\hline
\end{tabular}

Figure 16. Nominal Test matrix used in TDT Test 613.

used in Test 613 was modified as shown in figure 18. In general, logarithmic sweeps of longer duration were used. The sweeps were better suited to the previously described ASE model optimization procedure. In addition, some antisymmetric control surface data were acquired. The most important change to the test matrix was the inclusion of GLAMode values of 1 and greater indicating that GLA control laws were evaluated.

A sample ParamID data set used for ASE model refinement is shown in figure 19. GLAMode 0 and TestMode 1 were used for this data set. All control surfaces received the same $2.5^{\circ}$ excitation signal. This figure shows time histories of the model rigid body positions (PZ and $\Theta$ ), a select set of strain gauges and accelerometers, and the wing control surface positions. The fuselage accelerometers are included as they are used as inputs to the trim control law, and the forward wing inboard and tail root strain gauges are show as these signals were used as inputs to the most successful version of the GLA control law. The aft wing control surface positions are a sum of the trim controller and the excitation signal. The trim controller did not use the forward wing surfaces so what is plotted is simply the sum of the bias values and the excitation signal. It should be pointed out that the forward wing control surfaces include the biases to help trim the model and bring the mean aft wing control surface commands closer to zero. Using the forward wing surfaces to help trim the model was an important part of testing in general, with different biases being used with different CG locations (static margins). This trimming procedure was necessary to keep the aft wing control surface commands from exceeding their physical limits.

Figures 20 and 21 show model responses to AOS sweeps. The format of these plots is essentially the same as what was previously described in figure 19 except that the frequency of the AOS vanes is also shown in the upper plots. The data plotted in figure 20 was acquired using GLAMode 0 and TestMode 1, and the data acquired in figure 21 shows was acquired using GLAMode $5 \mathrm{v} 6$ and TestMode 1. Forward wing outboard control surface motion can be seen in figure 21 where GLA was engaged. These data points were selected because they were among the last sets of data acquired during Test 614, and these same points will be further analyzed in the frequency domain below.

Test 614 was conducted over a period of approximately 6 weeks. Throughout this test, both the trim controller and the GLA control law were continuously refined. The general process was to design, implement, 


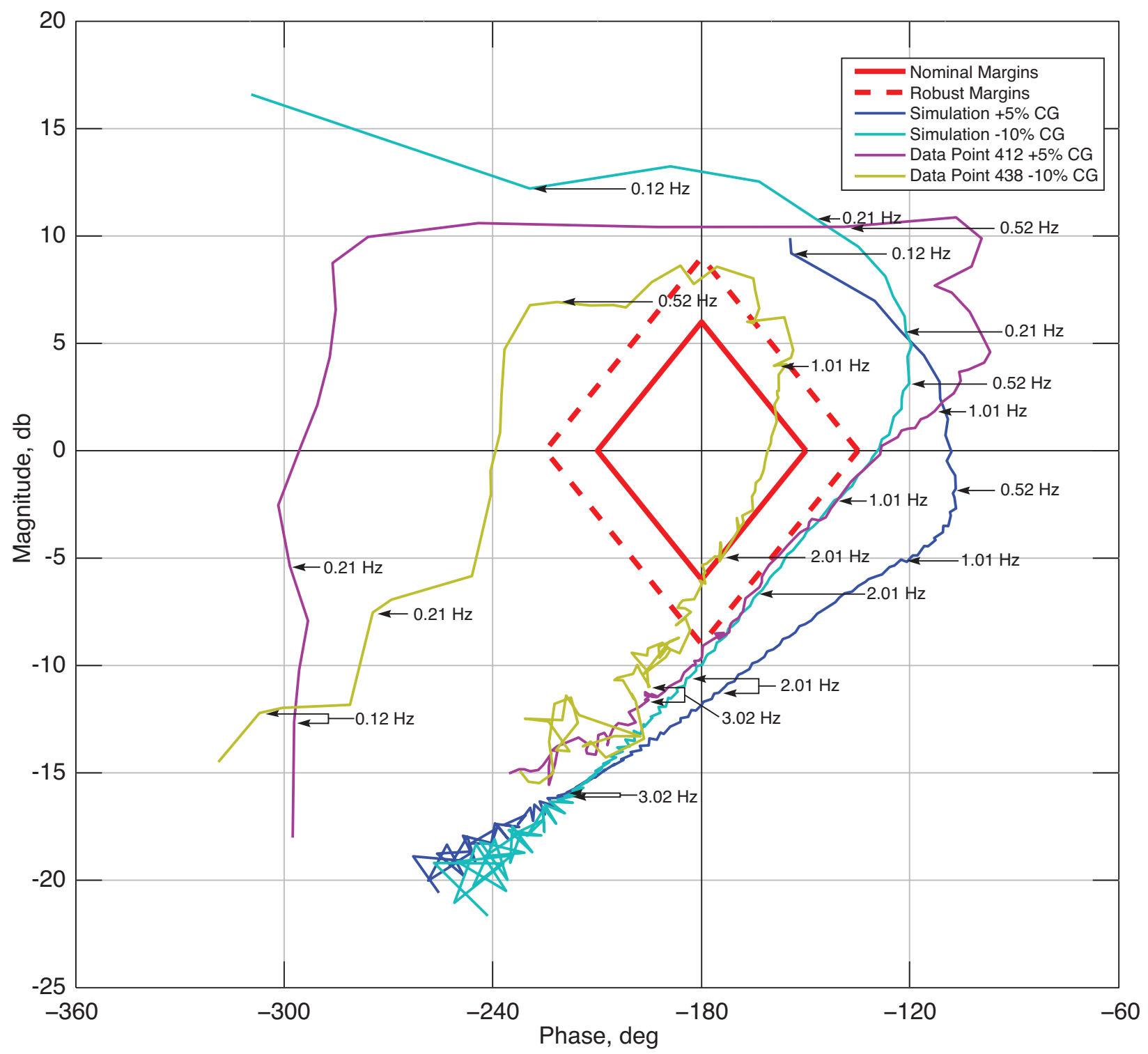

Figure 17. Nichols stability plot for initial trim controller gains with $+5 \%$ and $-10 \%$ static stability. Test 613 data points 412 and 438 plotted along with simulation results 


\begin{tabular}{|c|c|c|c|c|c|c|c|c|c|c|}
\hline & \multicolumn{3}{|c|}{ Boundary Condition } & & & & & & & \\
\hline & \multirow{3}{*}{ 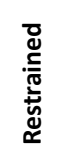 } & \multirow{3}{*}{ 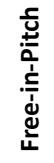 } & \multirow{3}{*}{$\stackrel{\stackrel{0}{0}}{\sum_{\bar{Z}}^{\infty}}$} & & & & & \multicolumn{2}{|c|}{ Static Margin $=+5,0,-5, \&-10 \%$} & \\
\hline & & & & & \multicolumn{2}{|c|}{ Sweep } & \multicolumn{2}{|c|}{ Symmetric } & \multicolumn{2}{|c|}{ Antisymmetric } \\
\hline & & & & GLAMode & Linear & Log & Frequency, $\mathrm{Hz}$ & Amplitude & Frequency, $\mathrm{Hz}$ & Amplitude \\
\hline \multicolumn{11}{|l|}{ TestMode1: } \\
\hline Tunnel Turbulence & $\mathrm{x}$ & $\mathrm{x}$ & $\mathrm{x}$ & $0,1,2 \ldots$ & & & - & - & & \\
\hline AOS Gust & & & $x$ & $0,1,2 \ldots$ & & & Dwells & $6^{\circ}$ & & \\
\hline AOS Gust & $x$ & $\mathrm{x}$ & $\mathrm{x}$ & $0,1,2 \ldots$ & & $120 \mathrm{~s}$ & $0.1-12$ & $6^{\circ}$ & & \\
\hline FWO Actuator & $x$ & $\mathrm{x}$ & $x$ & $0,1,2 \ldots$ & & $60 / 120 s$ & $0.1-20,0.1-4$ & $4^{\circ}$ & $0.1-20,0.1-4$ & $4^{\circ}$ \\
\hline FWM Actuator & $x$ & $\mathrm{x}$ & $\mathrm{x}$ & $0,1,2 \ldots$ & & $60 / 120 s$ & $0.1-20,0.1-4$ & $4^{\circ}$ & $0.1-20,0.1-4$ & $4^{\circ}$ \\
\hline FWI Actuator & $x$ & $\mathrm{x}$ & $x$ & $0,1,2 \ldots$ & & $60 / 120 s$ & $0.1-20,0.1-4$ & $4^{\circ}$ & $0.1-20,0.1-4$ & $4^{\circ}$ \\
\hline FW All Actuator & $x$ & $\mathrm{x}$ & $x$ & $0,1,2 \ldots$ & & $60 / 120 s$ & $0.1-20,0.1-4$ & $2.5^{\circ}$ & & \\
\hline AWO Actuator & $x$ & $\mathrm{x}$ & $x$ & $0,1,2 \ldots$ & & $60 / 120 s$ & $0.1-20,0.1-4$ & $4^{\circ}$ & $0.1-20,0.1-4$ & $4^{\circ}$ \\
\hline AWM Actuator & $x$ & $\mathrm{x}$ & $\mathrm{x}$ & $0,1,2 \ldots$ & & $60 / 120 \mathrm{~s}$ & $0.1-20,0.1-4$ & $4^{\circ}$ & $0.1-20,0.1-4$ & $4^{\circ}$ \\
\hline AWI Actuator & $x$ & $x$ & $x$ & $0,1,2 \ldots$ & & $60 / 120 s$ & $0.1-20,0.1-4$ & $4^{\circ}$ & $0.1-20,0.1-4$ & $4^{\circ}$ \\
\hline AW All Actuator & $x$ & $\mathrm{x}$ & $x$ & $0,1,2 \ldots$ & & $60 / 120 s$ & $0.1-20,0.1-4$ & $2.5^{\circ}$ & & \\
\hline All Actuator & $\mathrm{x}$ & $\mathrm{x}$ & $x$ & $0,1,2 \ldots$ & & $60 / 120 s$ & $0.1-20,0.1-4$ & $2.5^{\circ}$ & & \\
\hline TestMode 2 & & & $x$ & $0,1,2 \ldots$ & & $60 / 120 s$ & $0.1-20,0.1-4$ & maximized & & \\
\hline TestMode 3 & & $\mathrm{x}$ & $x$ & $0,1,2 \ldots$ & & $60 / 120 s$ & $0.1-20,0.1-4$ & maximized & & \\
\hline TestMode 4 & & & $x$ & $0,1,2 \ldots$ & & $60 / 120 \mathrm{~s}$ & $0.1-20,0.1-4$ & maximized & & \\
\hline TestMode 5 & & & $x$ & $0,1,2 \ldots$ & & $60 / 120 s$ & $0.1-20,0.1-4$ & maximized & & \\
\hline TestMode 6 & & & $x$ & $0,1,2 \ldots$ & & $60 / 120 s$ & $0.1-20,0.1-4$ & maximized & & \\
\hline TestMode 7 & & & $x$ & $0,1,2 \ldots$ & & $60 / 120 \mathrm{~s}$ & $0.1-20,0.1-4$ & maximized & & \\
\hline TestMode 8 & & $\mathrm{x}$ & & 0 & & & & & & \\
\hline TestMode 9 & & & $x$ & $0,1,2 \ldots$ & & $60 / 120 \mathrm{~s}$ & $0.1-20,0.1-4$ & maximized & & \\
\hline TestMode 10 & & & $x$ & $2,3,4 \ldots$ & & $60 / 120 s$ & $0.1-20,0.1-4$ & maximized & & \\
\hline TestMode 11 & & $\mathrm{x}$ & & 0 & & & & & & \\
\hline
\end{tabular}

Figure 18. Nominal test matrix used in TDT Test 614.

test, and evaluate the trim and GLA controllers. This process was repeated multiple times during the testing period. As the testing progressed, improved testing procedures were developed including more optimal trim values for the control surfaces and expanded WatchDog parameters which allowed better ParamID data sets to be acquired. These data sets were used to further refine the ASE model helping to improve the trim and GLA controller designs.

The trim controller was tuned to improve the stability margins and general performance based on the refined simulation model. The stability margin improvements were designed to achieve a nominal stability margin target of $\pm 6 \mathrm{db}$ of gain margin and $\pm 30^{\circ}$ of phase margin at all four of the target CG positions. The design margins were generally achieved although the nonlinear break in the slope of the pitching moment associated with the aft wing control surfaces tended to shift the pitch loop gain up and down depending on the required trim deflections. The nonlinear responses are shown in the appendix.

A classical design approach was used in the development of the GLA controller. The classical design process provided a more direct way to address this specific gust load alleviation problem. This approach also facilitated the controller being tuned based on actual test results that were not captured in the simulation modeling. Fourteen GLA control laws were designed, tested, and evaluated. The first eight control laws were implemented as separate modes as they were developed and could be selected by modifying the GLA Mode input. The final six GLA Modes altered versions of GLA Modes 4 and 5. The GLA Modes were known as: $2,6,7,8,9,3,4,5,4 \mathrm{v} 2,5 \mathrm{v} 2,5 \mathrm{v} 3,5 \mathrm{v} 4,5 \mathrm{v} 5$, and 5v6; and were developed and tested in the order listed. Reference 12 includes detailed descriptions of the various GLA control law designs. The GLA controllers included alterations to the mix of control surfaces used by the trim controller and the inclusion of forward wing inboard and tail boom root strain gauge feedback along with some basic first and second order filters.

The GLA controller with the best performance in terms of minimizing strain response was GLA Mode 5v6. This controller utilized feedback from the averaged forward wing inboard strain gauges along with the tail boom root strain gauge. A block diagram of this control law is shown in figure 22. It used three inputs that were combined, filtered and then distributed to four control surfaces. The inputs were mixed together using weights that enhanced the observability of the first forward wing bending mode while reducing the observability of the second forward wing bending mode. The result was then passed through a series of filters. 


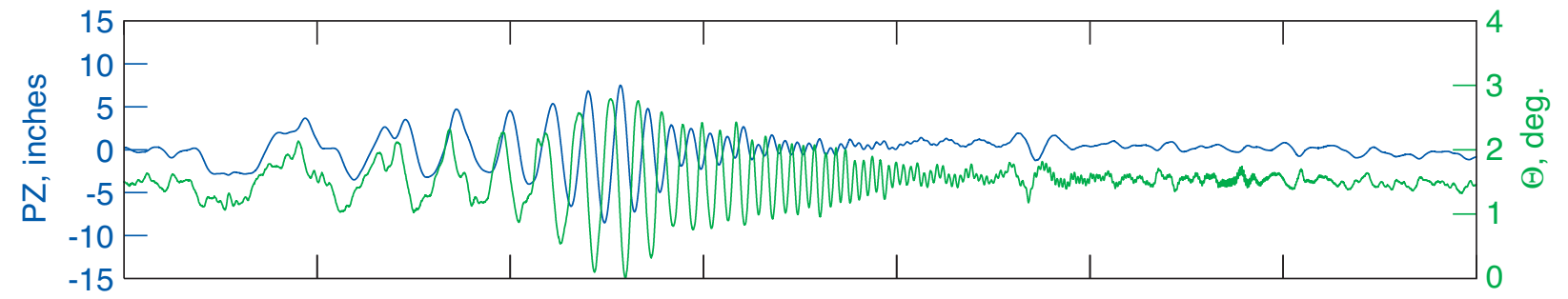

Strain Gauges: Blue=Forward Wing Left Inboard, Green=Forward Wing Right Inboard, \& Red=Tail Root

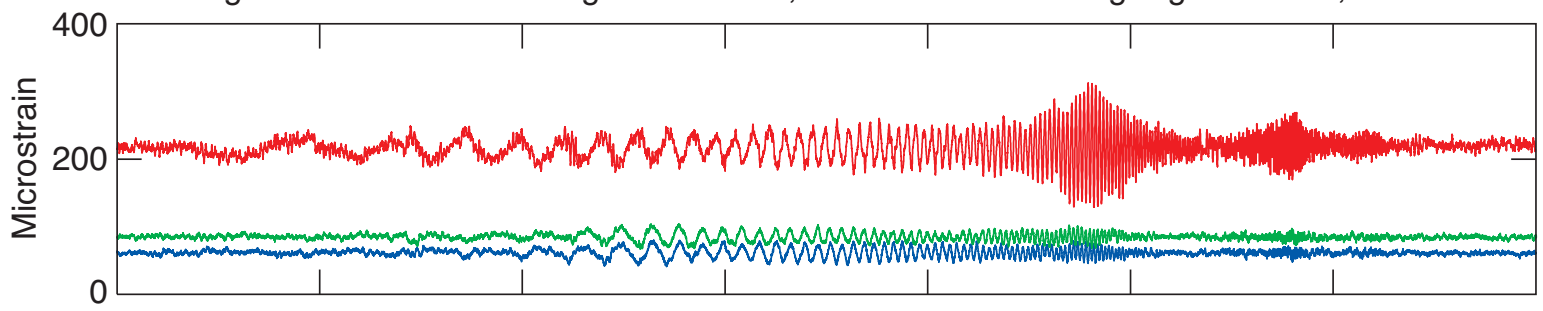

Fuselage Accelerometers: Blue=Aft, Green=Forward

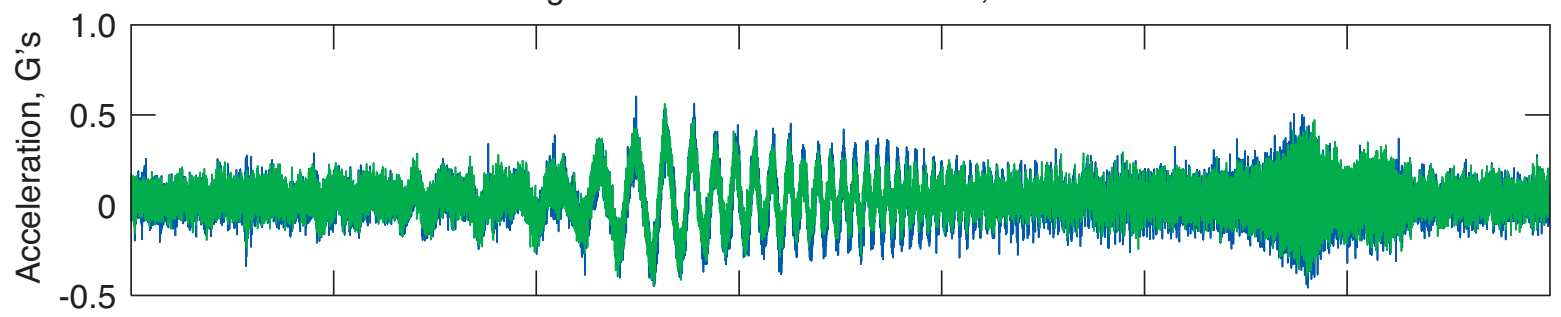

Aft Wing Control Surfaces : Blue=Outboard, Green=Midboard, Red=Inboard

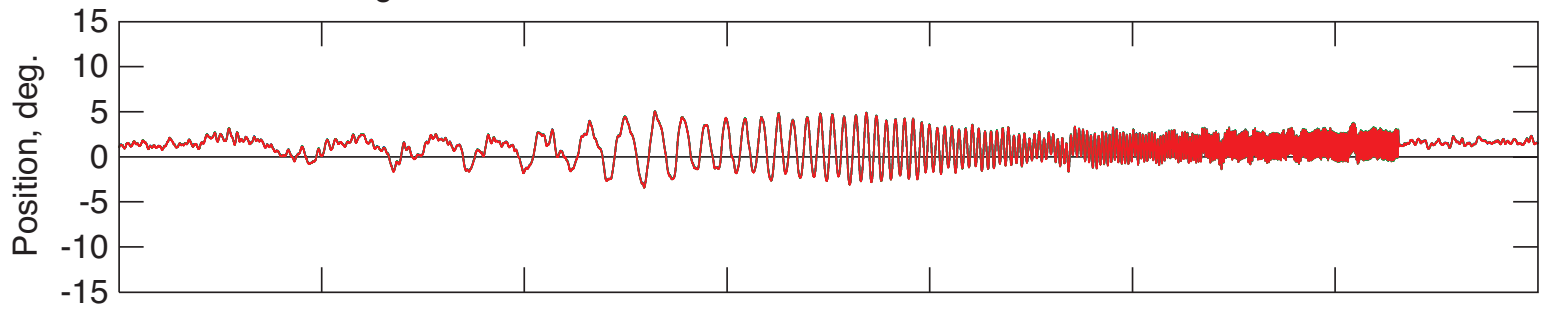

Forward Wing Control Surfaces: Blue=Outboard, Green=Midboard, Red=Inboard

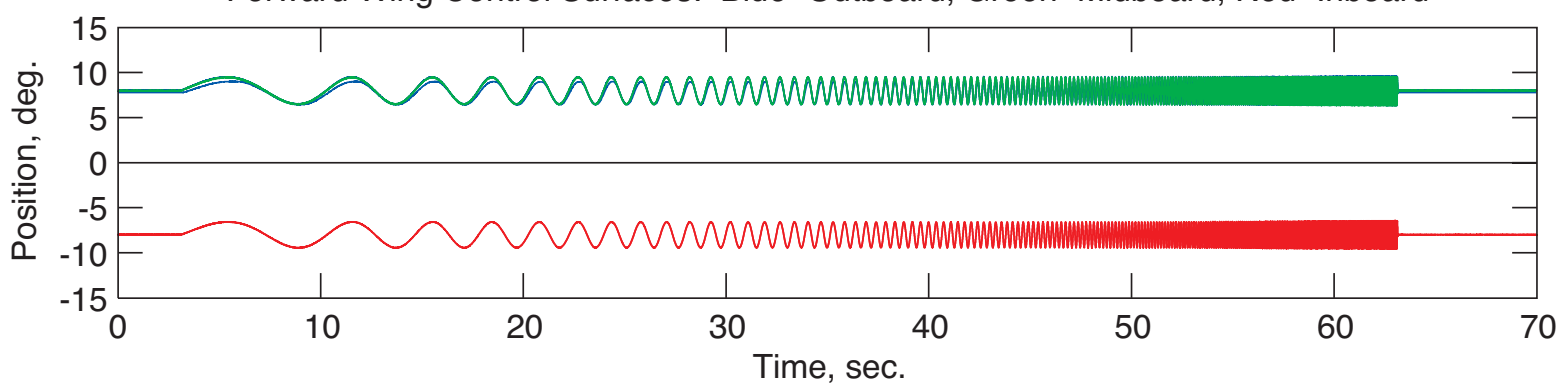

Figure 19. Symmetric, all wing control surface sweep 0.1-20 Hz. Amplitude $=2.5^{\circ}$, Test 614 , data point 1019, GLAMode 0, TestMode 1, static margin=-10\%. 


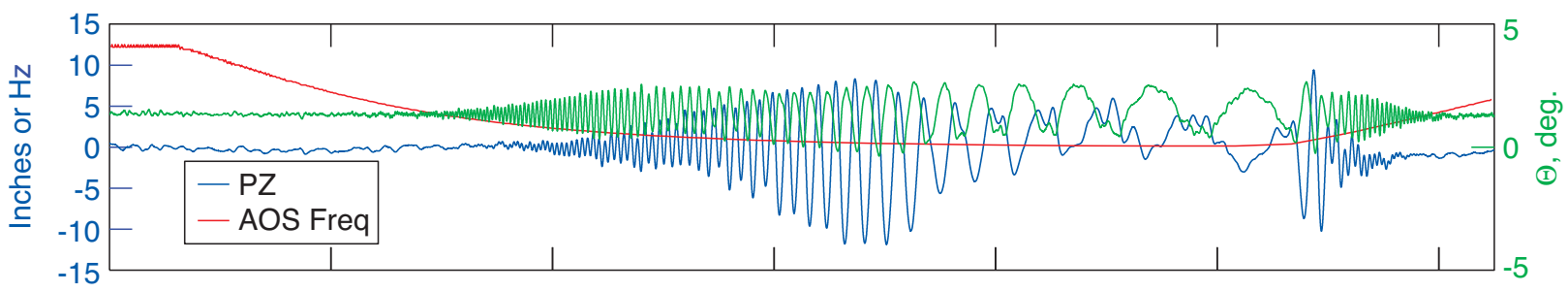

Strain Gauges: Blue=Forward Wing Left Inboard, Green=Forward Wing Right Inboard, \& Red=Tail Root

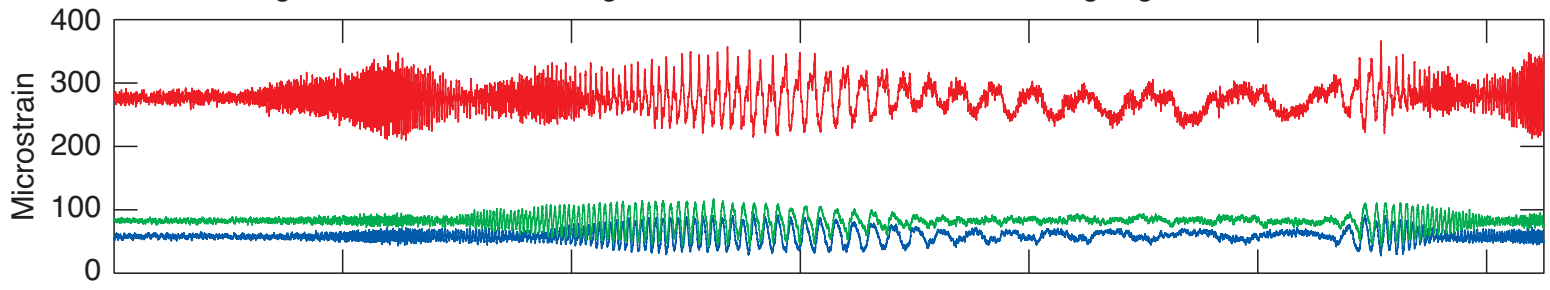

Fuselage Accelerometers: Blue=Aft, Green=Forward

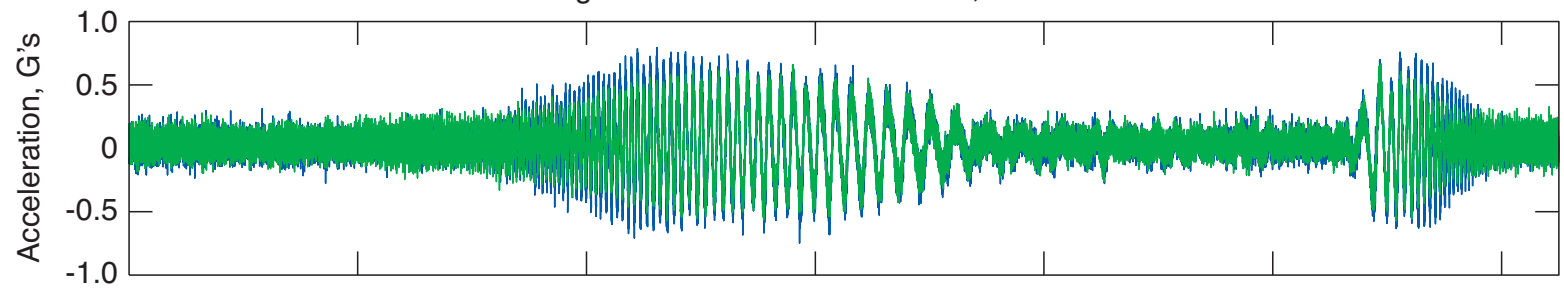

Aft Wing Control Surfaces : Blue=Outboard, Green=Midboard, Red=Inboard

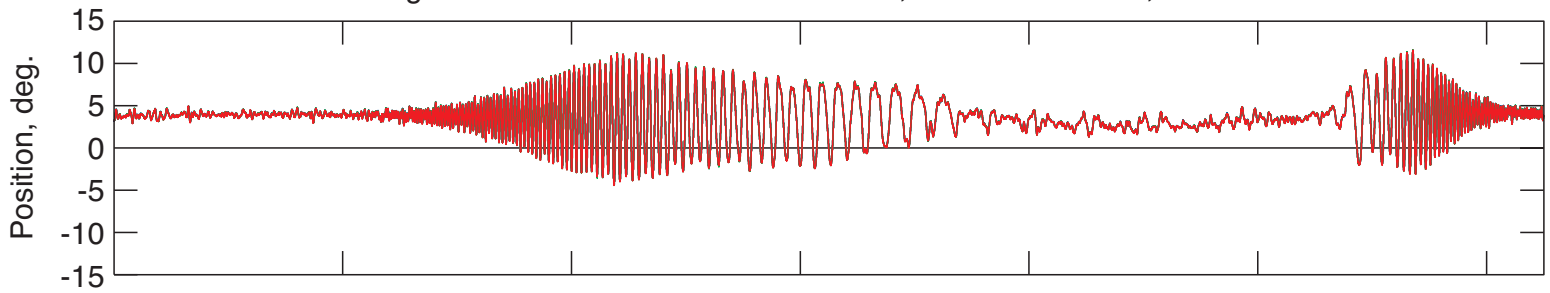

Forward Wing Control Surfaces: Blue=Outboard, Green=Midboard, Red=Inboard

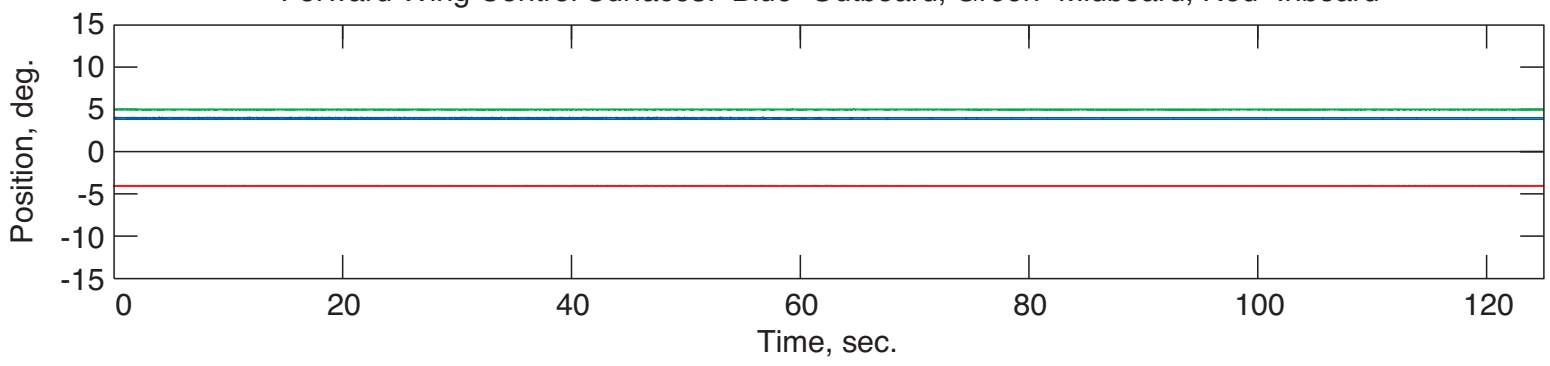

Figure 20. AOS sweep 012-.1 Hz. Test 614, data point 1750, GLAMode 0, TestMode 1, static margin=-10\%. 

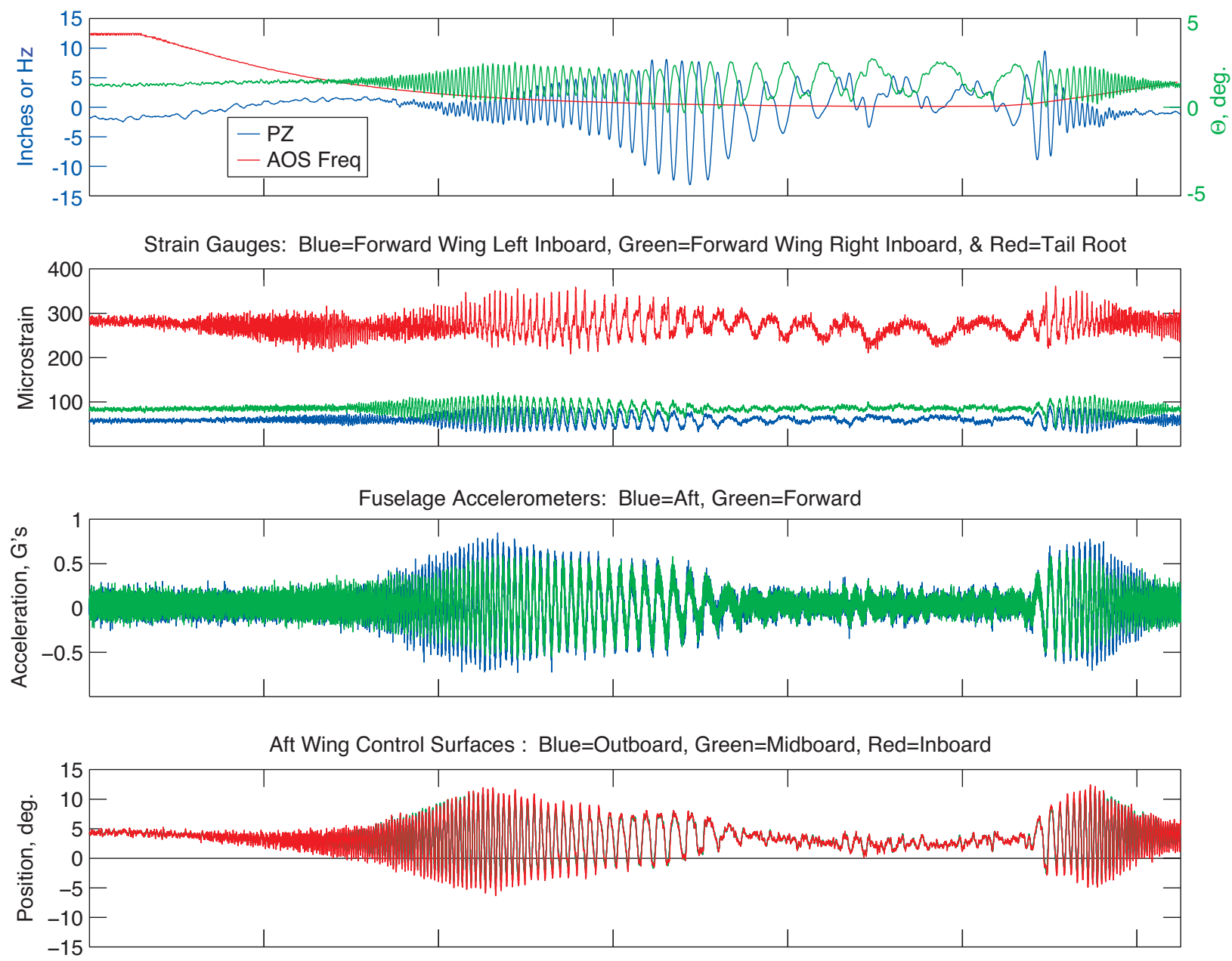

Forward Wing Control Surfaces: Blue=Outboard, Green=Midboard, Red=Inboard

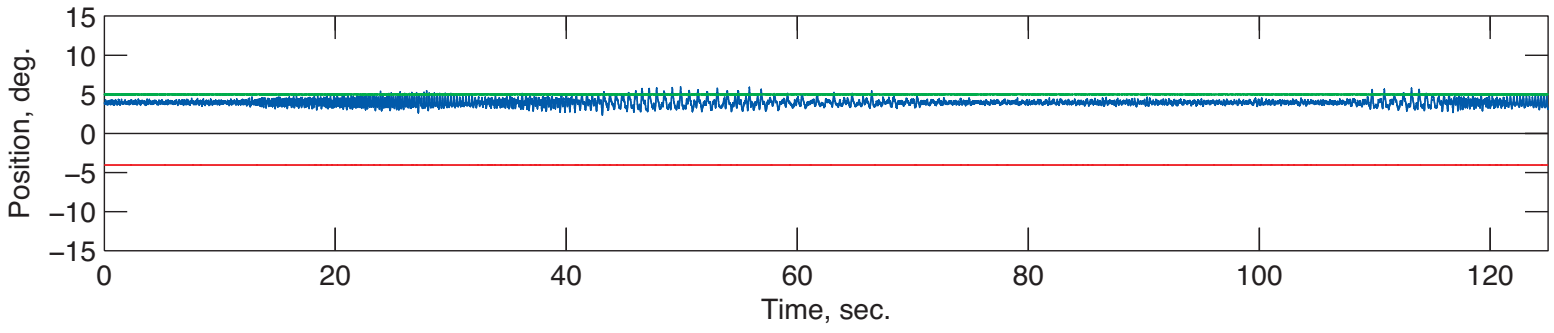

Figure 21. AOS sweep 12-0.1 Hz. Test 614, data point 1765, GLAMode 5 v6, TestMode 1, static margin=-10\%. 
The first filter was a second-order high pass filter with a frequency of $1 \mathrm{~Hz}$ and a damping ratio of 0.5 . The second filter consisted of a first-order lead with a frequency of $3 \mathrm{~Hz}$ and a first-order lag with a frequency of $3.57 \mathrm{~Hz}$. The third filter consisted of a first-order lag with a frequency of $20.23 \mathrm{~Hz}$. This filtered result was then scaled and distributed to the forward wing outboard surfaces and the aft wing inboard surfaces.

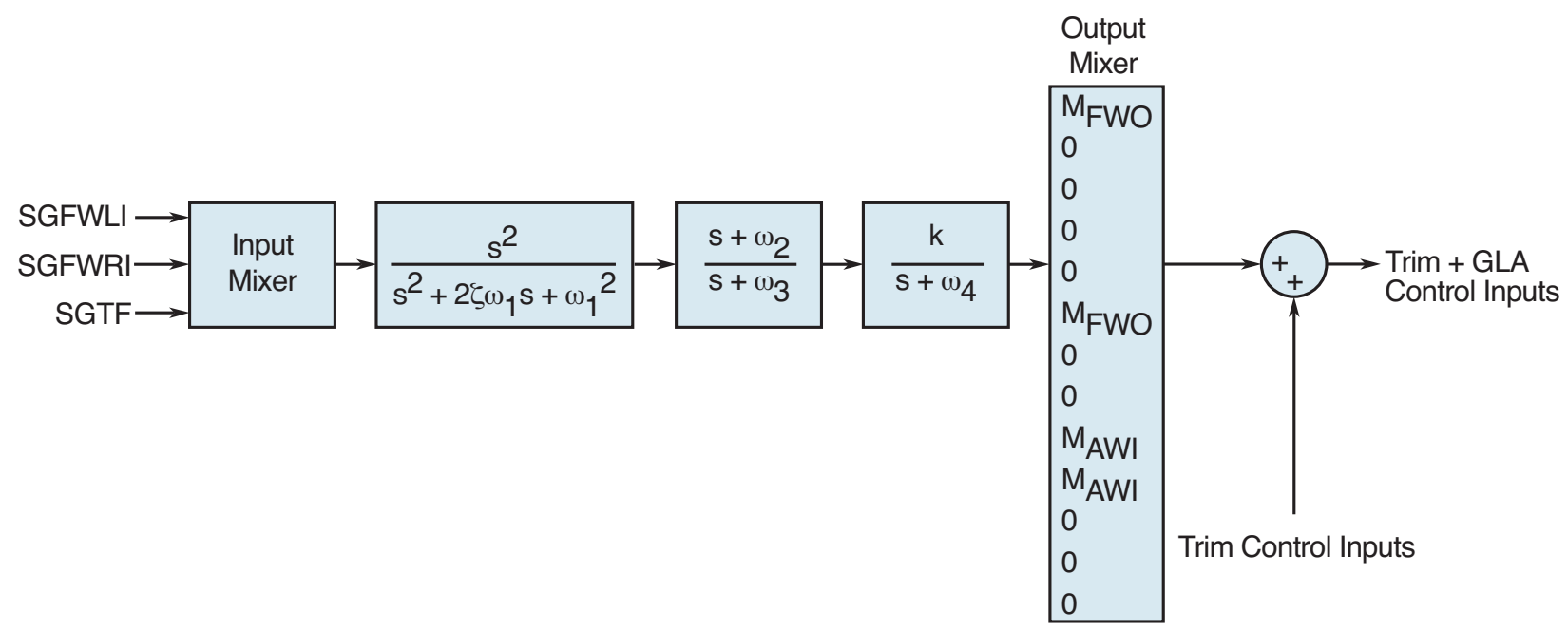

Figure 22. GLAMode 5v6 block diagram.

Plots of the the frequency response of the average forward wing strain and the tail root strain acquired during AOS sweeps with GLAMode 0 (trim control only) and GLAMode 5v6 (trim control + GLA) are shown in figure 23. Each plotted data set is composed of two data records that contained a sweep from 0.1 to $12 \mathrm{~Hz}$ and a sweep from 3 to $12 \mathrm{~Hz}$. Here, a $5 \mathrm{db}$ reduction in the first flexible mode forward wing inboard strain response and a $6 \mathrm{db}$ of reduction in the first flexible mode tail strain response can be seen in figures $23 \mathrm{a}$ and $\mathrm{b}$, respectively. These reductions were achieved without degrading (increasing response) in other modes.

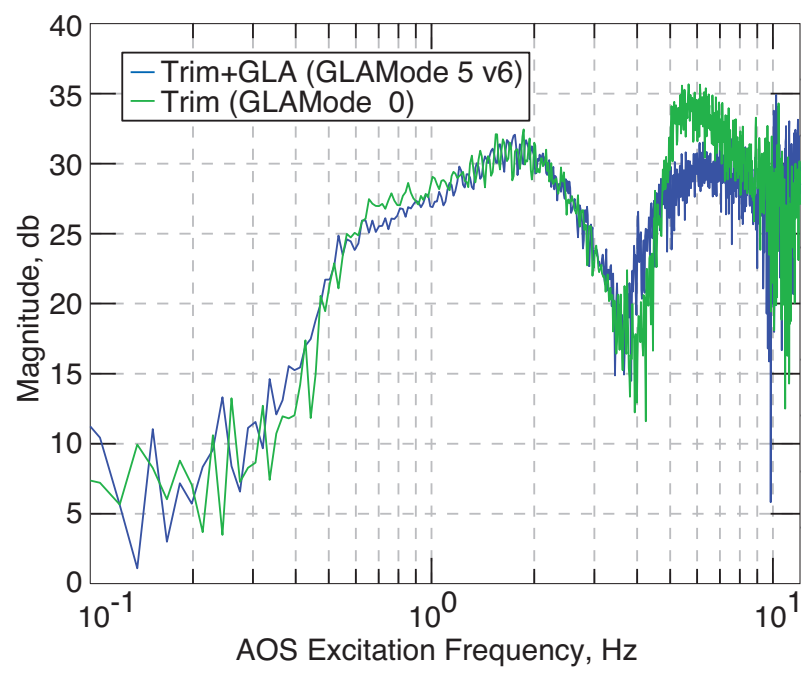

(a) Average forward wing inboard strain.

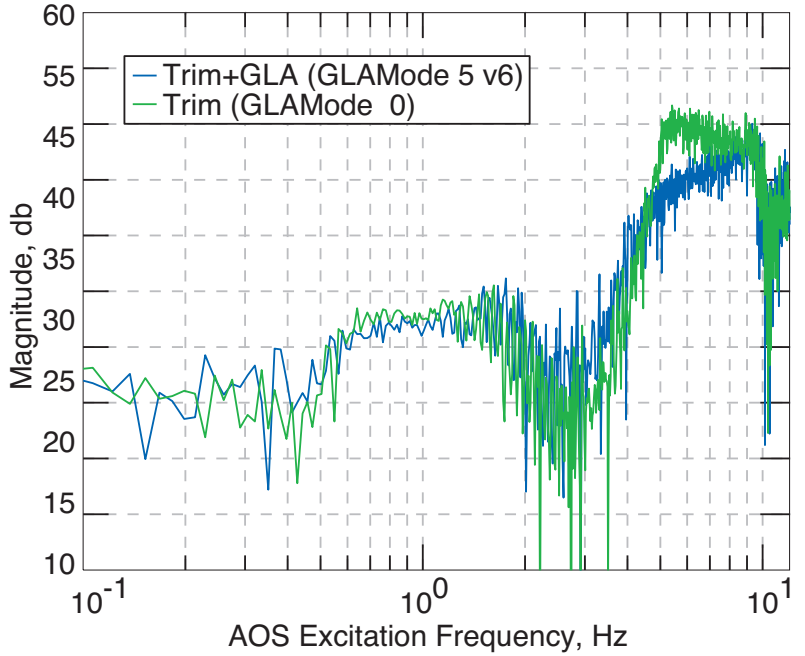

(b) Tail root strain.

Figure 23. Tail root and forward wing root strain response to AOS. Test 614, data points 1750, 1769, 1765, and 1770.

A Nichols plot for the $-10 \%$ static stability margin case where TestMode 3 was used to acquire the data is shown in figure 24a. This plot includes both data from the trim controller only and for the trim controller with GLA Mode 5v6 active. The plot shows that there is little impact to the pitch loop due to the addition of the GLA controller. A more enhanced view of the stability margins is shown in figure $24 \mathrm{~b}$, which shows 


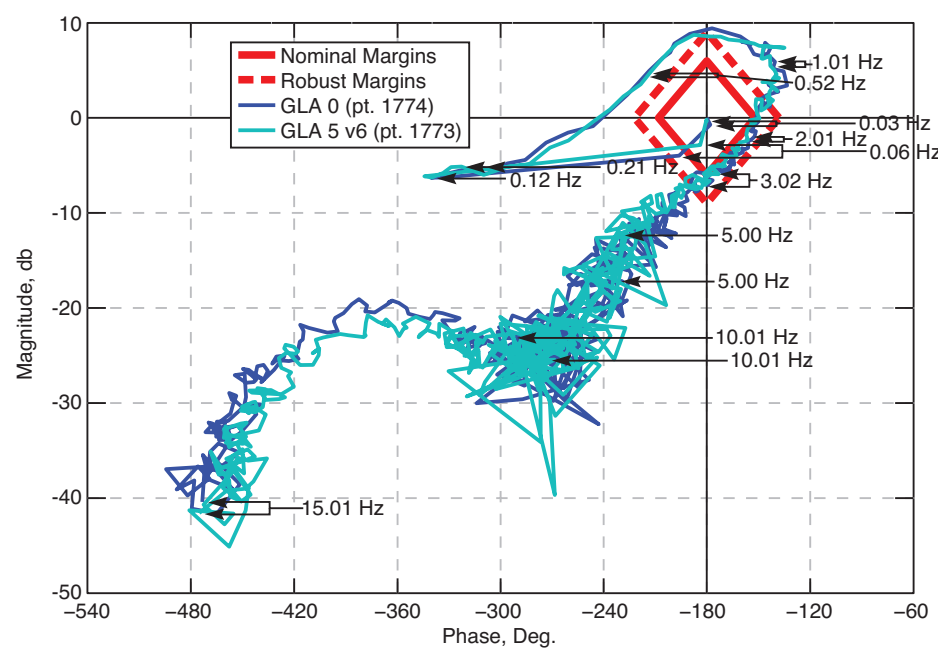

(a) Nominal view.

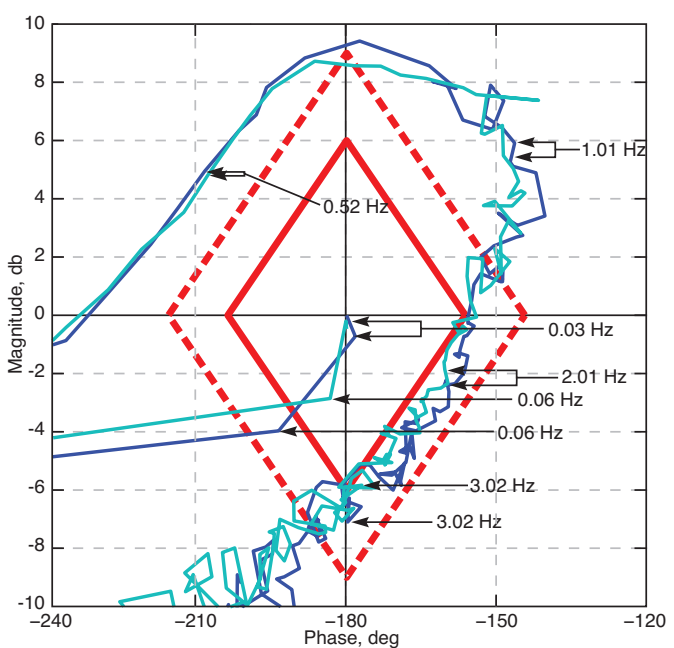

(b) Detail.

Figure 24. Nichols plot of trim (GLAMode 0) and trim+GLA (GLAMode 5v6) controllers. Test 614, data points 1774 and 1773

the desired $6 \mathrm{db}$ of gain margin and $30^{\circ}$ of phase margin.

\section{Concluding Remarks}

In the summer of 2010, the Air Force Research Laboratory (AFRL), Boeing, and NASA Langley Research Center successfully completed the third of a series of three wind-tunnel tests of an aeroelastically scaled windtunnel model of a joined-wing SensorCraft vehicle concept. The first of these tests was conducted on sting and balance. The second and third tests used a new, two-degree-of-freedom support system. This model support allowed the full-span model to translate vertically and rotate in pitch, allowing better simulation of the vehicle's rigid-body modes. The large size of the joined-wing model along with the rigid body degrees-offreedom afforded by the new mount system, created many unique challenges to successfully and safely flying the model in the tunnel and meeting the test objectives. This paper has provided an overview of the AEI joined-wing wind-tunnel tests. Descriptions of the hardware including the wind-tunnel, the wing model, the model support system, and other supporting systems developed for this program were provided. The design of the trim and gust load alleviation control systems were also described. Trimmed flight at $-10 \%$ static margin and a reduction of structural response of at least $50 \%$ were successfully demonstrated.

\section{References}

\footnotetext{
${ }^{1}$ Martinez, J., "An overview of SensorCraft capabilities and key enabling technologies," 26th AIAA Applied Aerodynamics Conference, No. AIAA-2008-7185, Honolulu, Hawaii, Aug. 2008.

${ }^{2}$ Lockyer, A. J., Drake, A., Bartley-Cho, J., Vartio, E., Solomon, D., and Shimko, T., "HIGH LIFT OVER DRAG ACTIVE (HiLDA) WING; Delivery Order 0007: HiLDA Wing Program," Tech. Rep. AFRL-VA-WP-TR-2005-3066, Northrop Grumman Corporation, 2005.

${ }^{3}$ Vartio, E., Shimko, A., Tilmann, C. P., and Flick, P. M., "Structural Modal Control and Gust Load Alleviation for a SensorCraft Concept," 46th AIAA/ASME/ASCE/AHS/ASC Structures, Structural Dynamics and Materials Conference, No. AIAA-2008-7185, Austin, Texas, April 2005.

${ }^{4}$ Silva, W., Vartio, E., Shimko, A., Kvaternik, R. G., Eure, K. W., and Scott, R. C., "Development of Aeroservoelastic Analytical Models and Gust Load Alleviation Control Laws of a SensorCraft Wind-Tunnel Model Using Measured Data," 47th AIAA/ASME/ASCE/AHS/ASC Structures, Structural Dynamics and Materials Conference, No. AIAA-2006-1935, Newport, Rhode Island, May 2006.

${ }^{5}$ Scott, R. C., Vetter, T. K., Penning, K. B., Coulson, D. A., and Heeg, J., "Aeroservoelastic Testing Of A Sidewall Mounted Free Flying Wind-Tunnel Model," 26th AIAA Applied Aerodynamics Conference, No. AIAA-2008-7186, Honolulu, Hawaii, Aug. 2008.

${ }^{6}$ Bartley-Cho, J. and Henderson, J., "Design and Analysis of HiLDA/AEI Aeroelastic Wind Tunnel Model," 26th AIAA Applied Aerodynamics Conference, No. AIAA-2008-7191, Honolulu, Hawaii, Aug. 2008.

${ }^{7}$ Vartio, E. and Shaw, E., "GLA Flight Control System Design for a SensorCraft Vehicle," 26th AIAA Applied Aerody-
} 
namics Conference, No. AIAA-2008-7192, Honolulu, Hawaii, Aug. 2008.

${ }^{8}$ Penning, K., Zink, P. S., Wei, P., De La Garza, A. P., and Love, M. H., "GLA and Flutter Suppression for a SensorCraft Class Concept Using System Identification," 26th AIAA Applied Aerodynamics Conference, No. AIAA-2008-7188, Honolulu, Hawaii, Aug. 2008.

${ }^{9}$ Love, M. H. and et. al., "Final Report for the Aerodynamic Efficiency Improvement Contract No.: FA8650-05-C-3501," Tech. Rep. FMZ-9454, Lockheed Martin Corporation, 2008.

${ }^{10}$ Reichenbach, E., "Aeroservoelastic Design and Test Validation of the Joined Wing SensorCraft," 26th AIAA Applied Aerodynamics Conference, No. AIAA-2008-7189, Honolulu, Hawaii, Aug. 2008.

${ }^{11}$ LeDoux, S., Vassberg, J., and Fatta, G., "Aerodynamic Cruise Design of a Joined Wing SensorCraft," 26th AIAA Applied Aerodynamics Conference, No. AIAA-2008-7190, Honolulu, Hawaii, Aug. 2008.

${ }^{12}$ Reichenbach, E., Castelluccio, M., Sexton, B., and Scott, R., "Aerodynamic Efficiency Improvement Final Report Volume 2: Aeroservoelastic Test Program," AFRL Contractor Report FA8650-05-C-3500, Boeing Research and Technology Computational Sciences, 2010.

${ }^{13}$ Reichenbach, E. and Sexton, B., "Joined-Wing SensorCraft Aeroservoelastic Wind Tunnel Test Program," 52nd AIAA/ASME/ASCE/ASC Structures, Structural Dynamics and Materials Conference, Denver Colorado, April 2011, Submitted for Publication.

${ }^{14}$ Scott, M. J., Enke, A., and Flanagan, J., "SensorCraft Free-Flying Aeroservoelastic Model: Design and Fabrication," 52nd AIAA/ASME/ASCE/ASC Structures, Structural Dynamics and Materials Conference, Denver Colorado, April 2011, Submitted for Publication.

${ }^{15}$ Sharma, V. and Reichenbach, E., "Development of an Innovative Support System for SensorCraft Model," 52nd AIAA/ASME/ASCE/ASC Structures, Structural Dynamics and Materials Conference, Denver Colorado, April 2011, Submitted for Publication.

${ }^{16} \mathrm{Heeg}$, J. and Morelli, G., "Evaluation of simultaneous multi-sine excitation of the Joined Wing aeroelastic wind tunnel model," 52nd AIAA/ASME/ASCE/ASC Structures, Structural Dynamics and Materials Conference, Denver Colorado, April 2011, Submitted for Publication.

${ }^{17}$ Staff of the Aeroelasticity Branch, "The Langley Transonic Dynamics Tunnel," Langley Working Paper LWP-799, Sept. 1969.

${ }^{18}$ Corliss, J. M. and Cole, S. R., "Heavy Gas Conversion of the NASA Langley Transonic Dynamics Tunnel," Proceedings of the 20th Advanced Measurements and Ground Testing Technology Conference, No. 98-2710, Albuquerque, NM, June 1998.

${ }^{19}$ Cole, S. R. and Rivera Jr, J. A., "The New Heavy Gas Testing Capability in the NASA Langley Transonic Dynamics Tunnel," Royal Aeronautical Society Wind Tunnels and Wind Tunnel Test Techniques Forum, No. 4, Cambridge, UK, April 1997.

${ }^{20}$ Perry, B., Cole, S. R., and Miller, G. D., "Summary of an Active Flexible Wing Program," AIAA Journal of Aircraft, Vol. 32, No. 1, 1995, pp. 10-15.

\section{Appendix A - Control Surface Actuator Description, Bench Testing, and In-Service Performance}

The flight control surface actuators are key elements in the overall flight control system. They needed to be fast and reliable and compact enough to fit within the wings. The control surface actuator requirements were established based on demonstrated capabilities in similar applications, the specific requirements of the JWS model, and preliminary estimates of the requirements to achieve the gust load alleviation objectives. The actuator requirements are shown in table 3 .

Table 3. JWS actuator requirements

\begin{tabular}{lc}
\hline \hline Metric & Value \\
\hline Travel limit & $\geq \pm 15^{\circ}$ \\
Phase shift at $20 \mathrm{~Hz}$ with $\pm 2^{\circ}$ command & $\leq 30^{\circ}$ \\
Phase shift at $30 \mathrm{~Hz}$ with $\pm 2^{\circ}$ command & $\leq 60^{\circ}$ \\
Gain at $\leq 25 \mathrm{~Hz}$ with $\pm 2^{\circ}$ command & $\leq-2 \mathrm{db}$ \\
Hysteresis & $\leq 0.1^{\circ}$ \\
Max torque & $\geq 120$ oz-in \\
\hline
\end{tabular}

The travel limits were set based primarily on the limitations imposed by the available thickness of the wing and supported by preliminary GLA simulations of the model response to the gust input. The phase shifts and gain (referred to together as bandwidth) were chosen so that the control surfaces would be effective at the first mode frequency of approximately $5 \mathrm{~Hz}$. The hysteresis requirement was based on past operational experience with similar actuator designs along with the need to maintain linear behavior for the trim and 
GLA control laws. The torque requirement was specified to account for the maximum hinge moment on the control surface and to provide the required acceleration to achieve the bandwidth.

Electric and hydraulic actuation methods were investigated. The performance of each type was evaluated against the actuator requirements to identify a suitable candidate. Electric actuation was the initially favored method because of its perceived simplicity and recent advances in the electric actuation technology. A number of electric actuator types were reviewed including hobby servos, military unmanned aerial vehicle (UAV) servos, and voice coil actuators. The hobby servos had enough torque, but were too slow. The UAV servos had a lot of torque and were faster than the hobby servos, but were still too slow, approximately 12 $\mathrm{Hz}$ bandwidth. The voice coil actuators had enough potential bandwidth and could be ganged together for enough torque, but the size of the actuators would have made packaging difficult to implement in the model wings. Hydraulic actuation had the advantage of historical demonstration of the required performance, recent operational experience of the TDT, and design and manufacturing experience of the model subcontractor, NextGen Aeronautics.

In the end, the electric actuation option was determined to be too risky to pursue, and hydraulic actuation was selected for the JWS control surface actuators. The hydraulic actuation system consisted of a rotary vane actuator, a servo valve, a position transducer, and the associated electronics and plumbing. The operating pressure was selected to be 1,000 psi. The rotary vane actuator was designed and built by NextGen with a 0.5 -in square vane and $\mathrm{a} \pm 15^{\circ}$ travel. The servo valve was initially baselined as a Moog Series 30 servo valve with the Moog E024 servo valve later replacing 10 of the 13 Series 30 servo valves in the design due to the E024s smaller size and lighter weight. The position transducer selected was a RSYN-8-30 RVDT with the associated signal conditioner, LDM-1000. After a significant design effort combined with much trial and error, the previously described performance objectives were largely met.

\section{A. Control Surface Actuator Bench Testing}

A test bench was created to evaluate the actuation system. The test bench could be configured to test both the Moog Series 30 and the EO24 servo valves with the actuator connected to the servo valve by a single manifold (0" hydraulic tubes) or using separate manifolds for the actuator and servo valve using 12 " or 36 " of hydraulic tubes. The goal was to ensure that the actuator performance would be sufficient at the extremes of the potential wind-tunnel model configurations.

The actuator test bench consists of several components. These include the integrated manifold, a remote servo valve manifold, and a number of adaptors and tubes. In all configurations, the actuator mounts directly to the integrated manifold while the servo valve can attach directly to the integrated manifold or to the remote servo valve manifold. Figure 25 shows these components in several different configurations. An actuator with the end-caps removed and the shaft and vane visible is shown in figure 25a. In the background of this photo, a series 30 servo valve is shown mounted to the integrated manifold with hydraulic supply and return tubes attached. Figure 25b shows the actuator attached to the integrated manifold. Using appropriate adaptors, an EO24 servo valve is shown in figure $25 \mathrm{c}$ connected via the 12 " tubes and remote servo valve manifold.

For the bench tests, the PID gains on the control loop were established by tracking a square wave command. Command and position are plotted in near real time on the dSpace1 host system, so the procedure for setting the gains is to start with zero integral and derivative gains, and increase the proportional gain until actuator instability and then back off approximately 20\%. The derivative gain is then adjusted to improve stability. Integral gain was not found to be necessary and was set to zero. The same proportional and derivative gains were used for all the Series 30 and EO24 servo valve experiments.

The initial series of experiments were designed to determine the optimal settings for the LDM 1000 signal conditioner. These experiments are described in detail in reference 12. Ultimately, it was determined that the best actuator response, in terms of phase lag, was obtained with the LDM 1000 filter set to $1000 \mathrm{~Hz}$ and the excitation frequency set to $2.5 \mathrm{KHz}$. The results of experiments with simulated control surface inertia are also documented in reference 12. Control surface inertia was found to have a small effect on actuator performance.

The bench testing showed that the actuator performance was sufficient in each of the hydraulic tube length configurations. The phase and gain responses are shown in figure 26. Four conditions are shown. The reference black line shows the response with the integrated manifold with a $1^{\circ}$ amplitude excitation. The blue line shows the response with the integrated manifold with a $3^{\circ}$ amplitude excitation. The green line shows the response with the 12 " long hydraulic tubes with a $3^{\circ}$ amplitude excitation. The red line shows the 


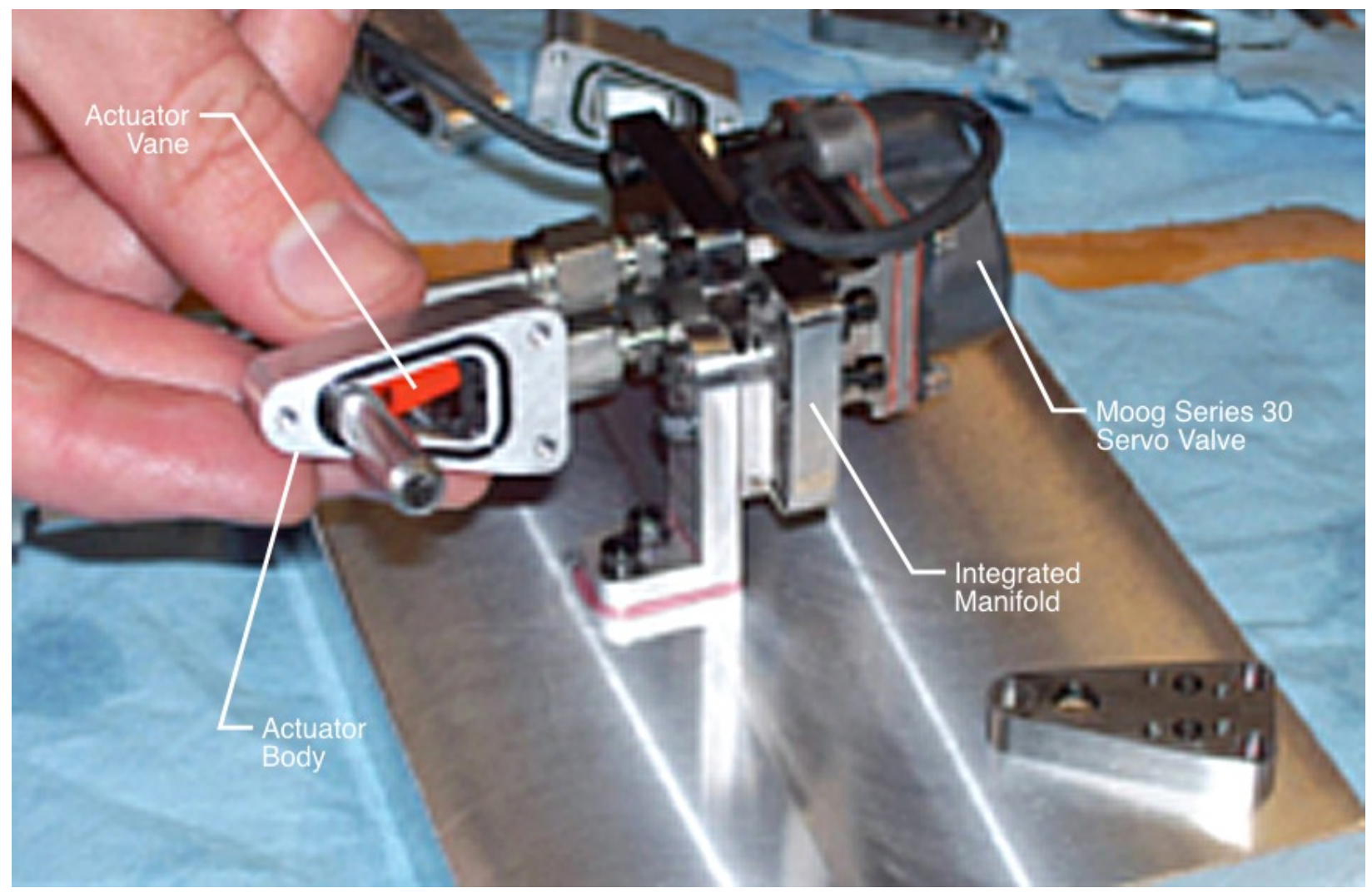

(a) Disassembled rotary vane actuator. Integrated manifold with series 30 servo valve installed shown in the background.

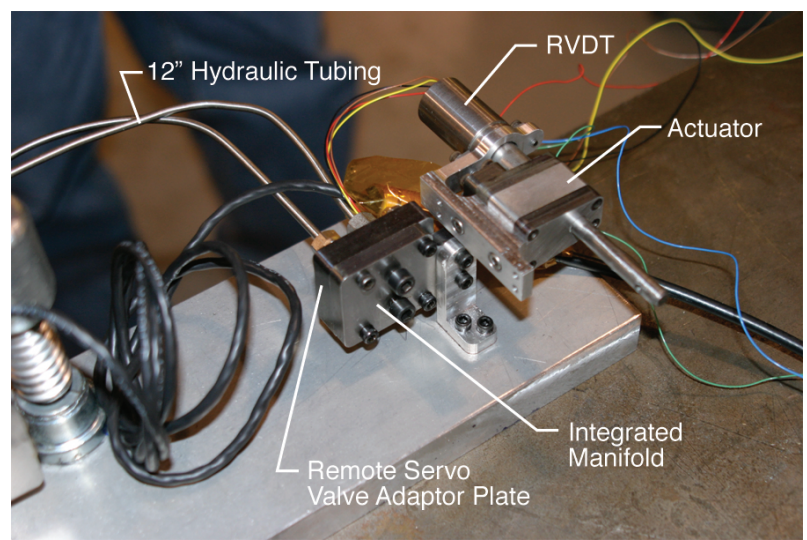

(b) Integrated manifold with actuator and RVDT installed. The remote servo valve adaptor with 12" tubes is also attached to the actuator manifold.

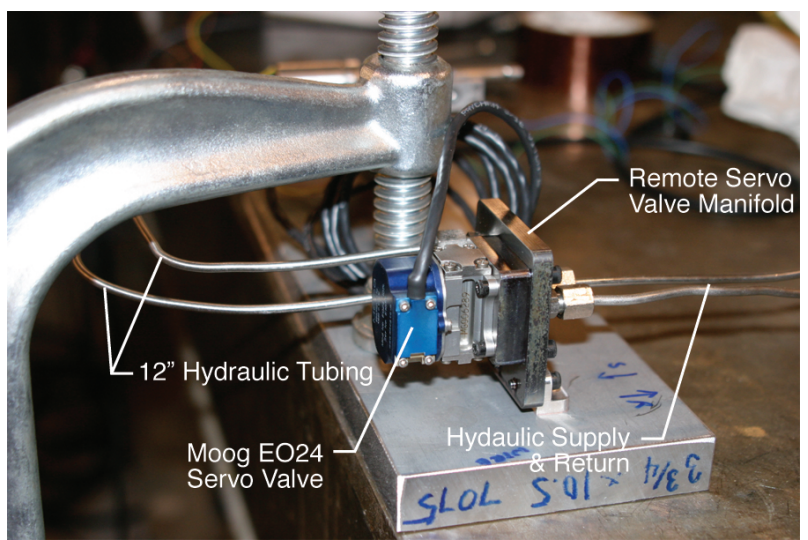

(c) Remote servo valve manifold with EO24 servo valve and 12 " tubes installed.

Figure 25. Photographs of actuator bench test rig in two different configurations. 
response with $36^{\prime \prime}$ long hydraulic tubes with the $3^{\circ}$ excitation. The sharp breaks in the phase plots are an indication of the servo valve hitting its flow rate limit. The responses for the longer hydraulic tubes show that the flow rate limit is hit earlier indicating that there are additional pressure drops associated with the use of the longer tubes although there is little difference between the 12" and 36" cases. At the time, this lack of difference was deemed satisfactory. Later review revealed that the servo valve manifold used for the 12 " and 36" test cases differed from the integrated (0") manifold in a critical way. The pictures of the two manifolds shown in figure 27 show that the manifold used for the 12" and 36" test cases (left) had very small ports compared to those on the integrated manifold (right). The much smaller ports add a significant amount of pressure drop, thereby decreasing the peak flow rate through the servo valve and providing an explanation for the sharp drop in performance when switching to the longer hydraulic tubes.
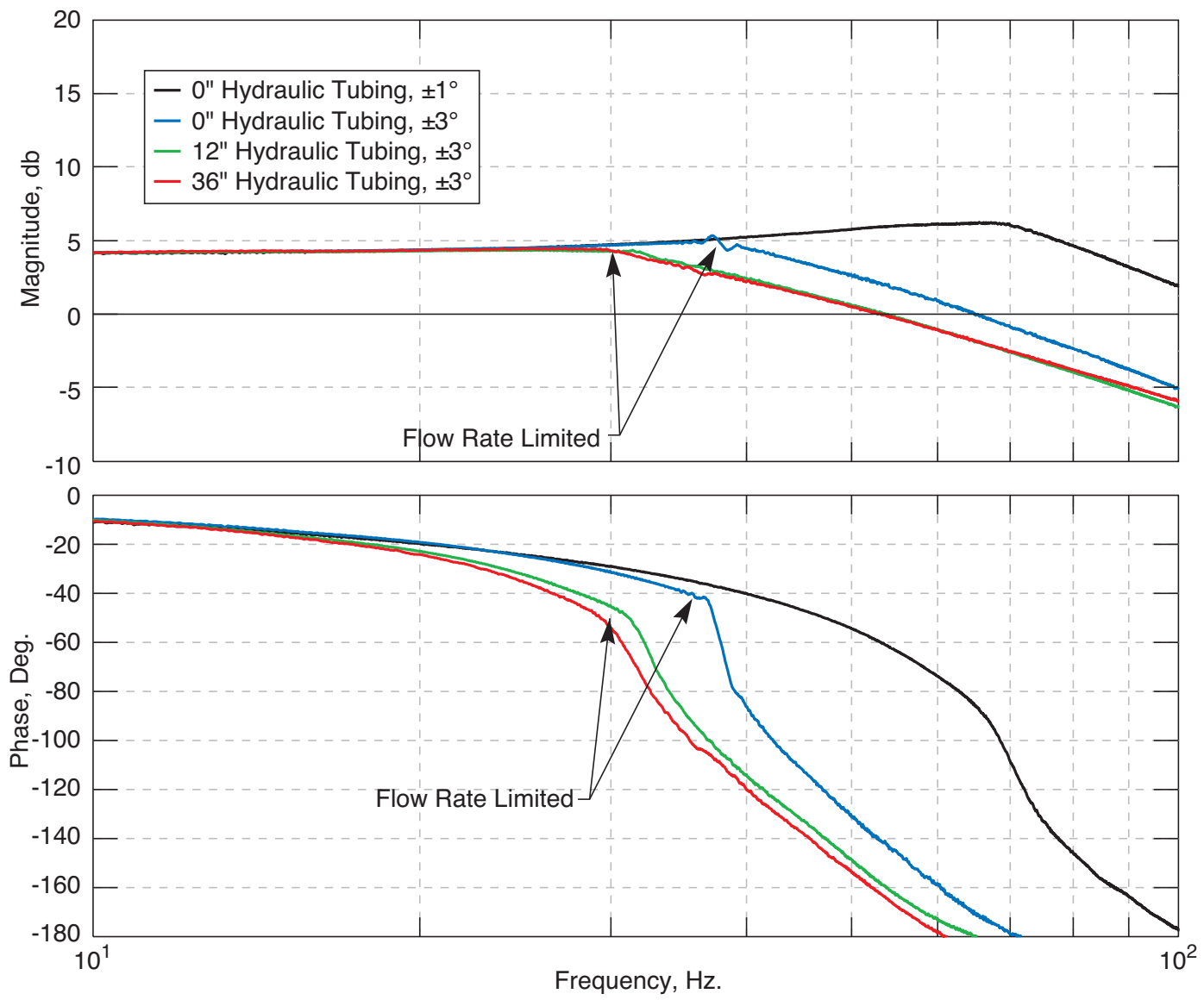

Figure 26. Actuator test bench performance data. Moog Series 30 servo valve.

\section{B. Model Actuator Frequency Response}

The joined-wing model arrived at the TDT in September 2008. Getting the actuators to perform reliably and consistently proved to be a challenge. Eventually, the control surface actuators reached a minimal state of functionality such that they could be used for static testing, but when surfaces were operated simultaneously their frequency response was well below what was observed in the bench test experiments. This performance was not a major problem for Test 606 as the primary purpose of this was to acquire steady data. After the completion of Test 606 in December 2008, the model was returned to the lab where actuator performance was reassessed.

Analyses of the pressure drops throughout the hydraulic system revealed the need for some modifications to the internal hydraulic system and a minor change to the actuators. The actuators were initially built with 0.030-in diameter ports for the hydraulic fluid. The pressure drop through these ports was excessive. 


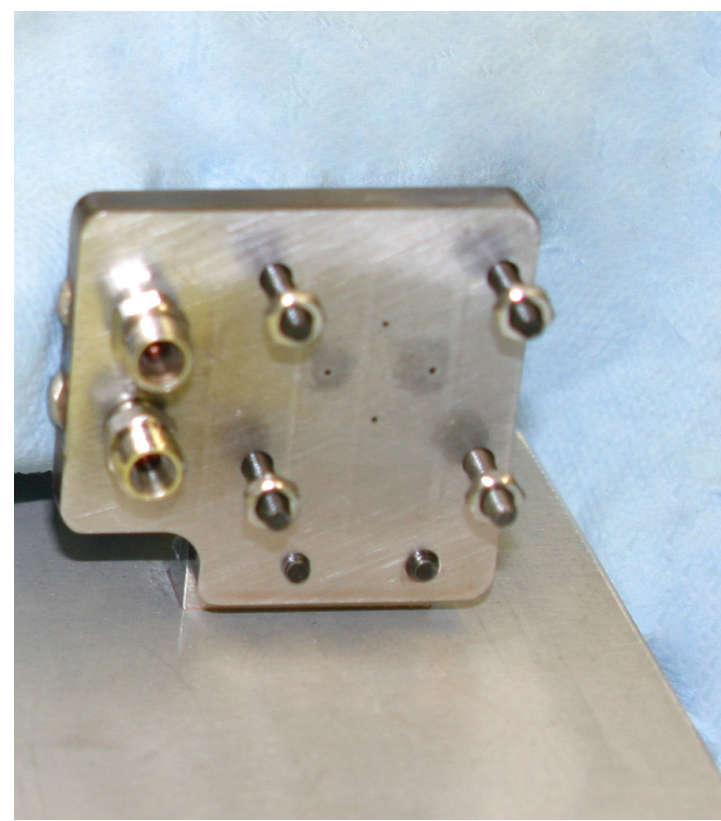

(a) Remote manifold.

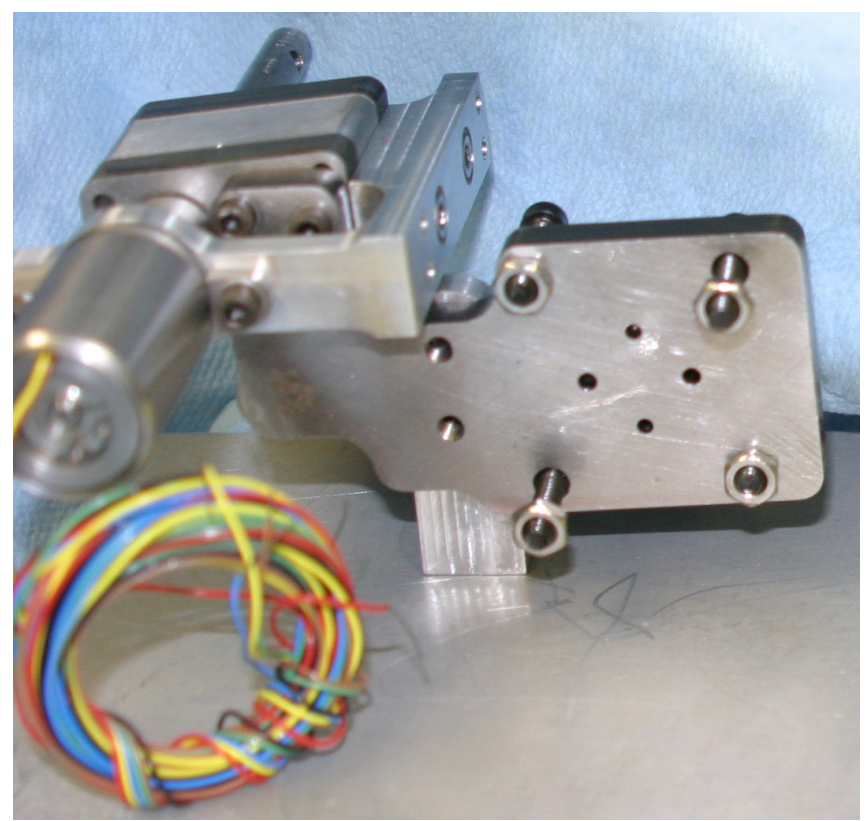

(b) Integrated manifold.

Figure 27. Test bench servo valve manifolds.

Analysis showed that increasing the port diameter to 0.045 in would significantly reduce the pressure drop. The external hydraulic flex tubing was determined to be too long and too small of a diameter, producing significant pressure drops when all of the actuators were operating. The external hydraulic tubing was replaced with shorter, larger diameter flex tubing. In addition, a number of hydraulic tubes within the model were replaced with tubes of larger diameter where feasible.

Photographs of the model internal hydraulic system used in Test 606 and in Tests 613 and 614 are shown in figure 28. One modification involved installing two hydraulic valves in the model. These valves could be configured in one of three ways: 1) Both Off; 2) By-Pass Mode where the external supply and return are connected with the model isolated; and 3) Normal Operation where the external supply and return are appropriately connected to the model hydraulic system. The valves minimized the chances of contaminating the model hydraulic system. Another modification was to replace some of the $1 / 8$ " ID hydraulic tubing in the model. Larger diameter tubing (1/4" ID) was installed in the fuselage, the forward wing, and the tail. In addition to the larger diameter tubing, an extra set of supply and return tubes was also added to the forward wing to increase flow capacity. The other modification was to plumb in the brake and snubber solenoid valves. The final modification was to add three 10 micron filters to the model to help minimize the risk of servo valve contamination. The final configuration is shown in figure 28b.

After these modifications were made, the performance of all of the actuators improved dramatically. Figure 29 shows the frequency response of a single actuator when excited individually and with all the actuators both before and after the modifications to the model hydraulic system. The bandwidth requirements described in table 3 had been met or exceeded.

Unfortunately, during the preparations for Test 613 , the servo valves failed twice. Both failures were due to contamination, and the valves had to be sent back to Moog for repair. The initial failure was thought to be associated with fabrication related contamination. After the second failure, it was determined that the TDT hydraulic system was the source of the contamination. The TDT 30 gpm hydraulic system was subsequently cleaned, two 3 micron filters were added in series to the model external supply tube, and the three 10 micron filters, noted earlier, were added to the model itself. These steps combined with a very thorough model flush procedure eliminated the problem of servo valve contamination.

The improvements to the model hydraulic system along with the lack of contamination resulted in much improved actuator performance and eliminated the need to individually tune the servo loops. For TDT tests 613 and 614 only proportional gains were needed with two different gains used, one for the series 30 valves and another for the EO24s. Figure 30 shows frequency response function estimates for all actuators when 


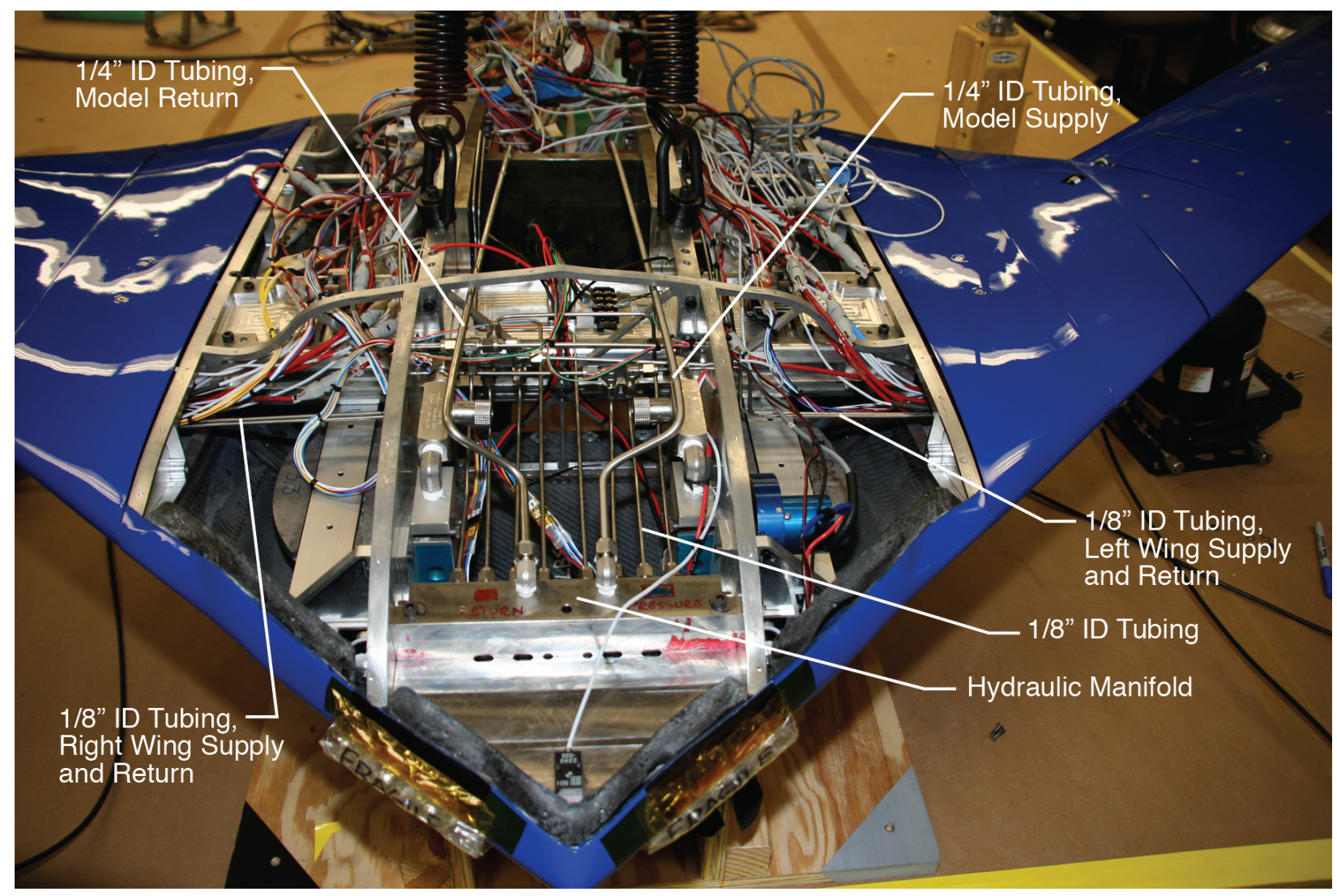

(a) Initial configuration used for Test 606 .

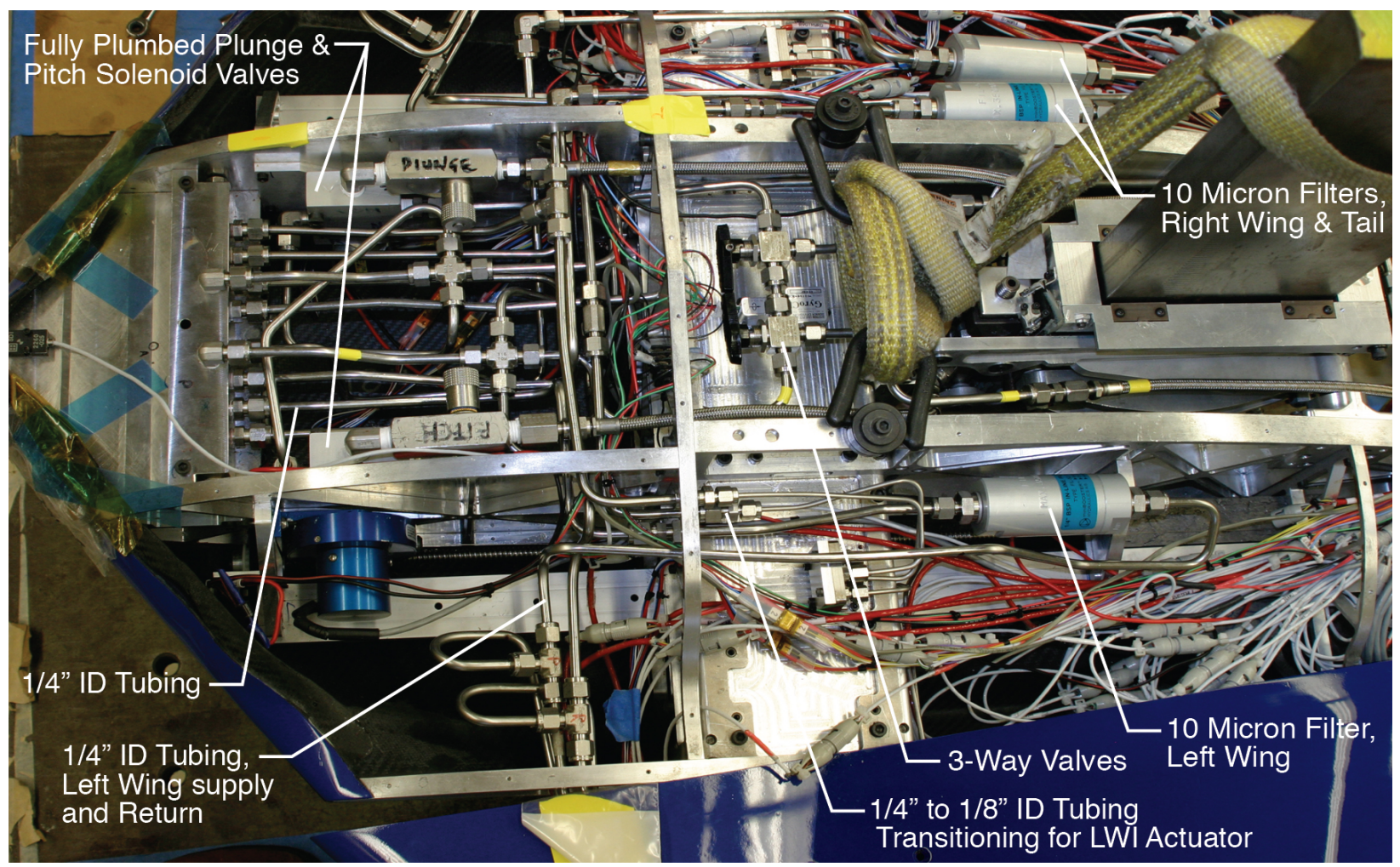

(b) Final configuration: 3-way valves, larger diameter tubing, 2nd set of tubes to forward wings, solenoid valves plumbed, and 10 micron filters added. Used in Tests 613 and 614.

Figure 28. JWS model internal hydraulic system. 

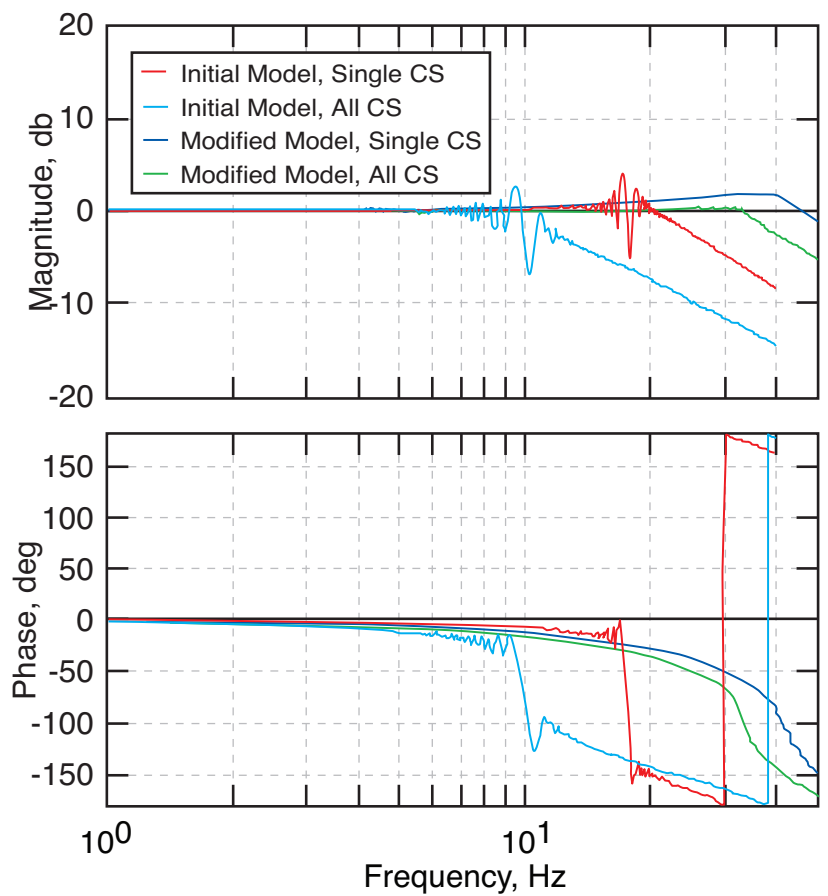

Figure 29. Forward-wing, left-mid-board control surface frequency response with the single and all control surfaces operating, before and after model plumbing modifications.
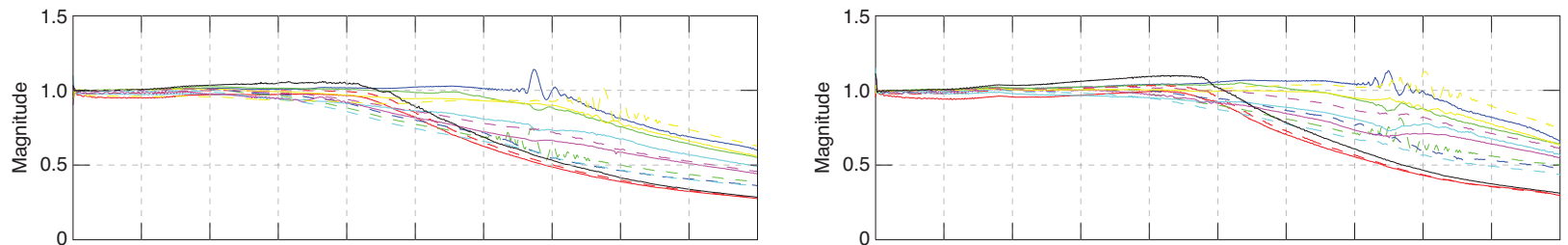

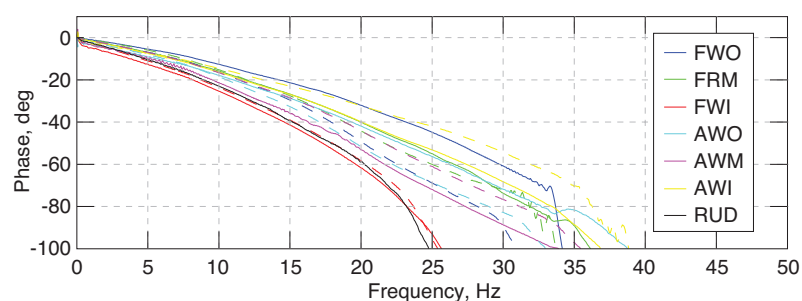

(a) Early in Test 613, data point 246.

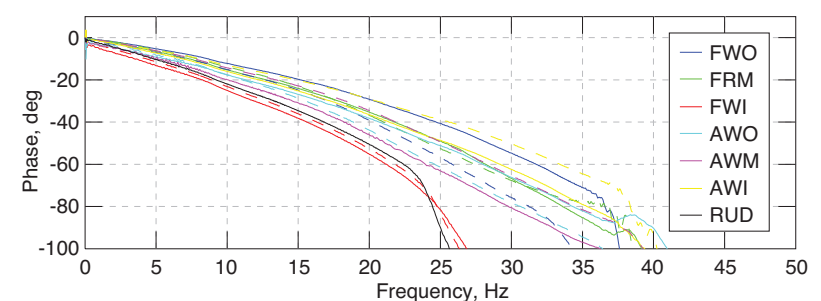

(b) End of Test 614, data point 1881.

Figure 30. Control surface frequency response function estimates, $\pm 3^{\circ}$ linear sine sweep excitation. Wing control surfaces on the left side of the model are shown using solid lines, and control surfaces on the right side of the model are shown using dashed lines. 
operated simultaneously. These data sets show that the control surface frequency response remained very consistent throughout Tests 613 and 614. It should also be pointed out that the three surfaces that use the series 30 servo valves (rudder and forward wing inboard control surfaces) tend to be grouped together especially in terms of phase. The other surfaces all use the EO24 valves but have varying tubing length between the servo valve and the actuator.

\section{Appendix B - Basic Aerodynamic Testing}

The initial wind-tunnel test of the JWS aeroelastic model was conducted with the model supported on a sting and force balance so that a full range of aerodynamic data could be collected. This data was used to refine the analytical models developed for flight control design.

The joined-wing model is shown in figure 31 attached to NASA balance 1630 among other sting components. Except for the balance cables which run inside the wing, all other instrumentation wiring and hydraulic flex tubing were taped to the outside of the sting. In order to allow the roll coupler to operate, the wires and hydraulic flex lines were grouped into two service loops as can be seen in the photo. The black wires running through the center slot in the test section floor run directly into the control room. While not shown in the photograph, these wires were grouped into a large service loop along the test section spitter plate allowing for sting pitch changes. These same wires were used with the beam mount in Tests 613 and 614 . The sting pitch and roll-coupler degrees-of-freedom enabled testing over a range of angles-of-attack (alpha) and sideslip (beta). The model was fully powered both electrically and hydraulically so that a multitude of control surface positions could be efficiently tested. Data from the on-board instrumentation system was recorded in addition to the balance forces.

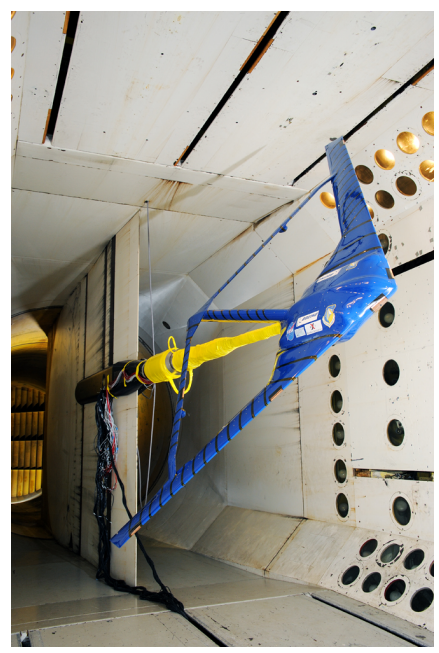

(a) Joined-wing SensorCraft model installed on the TDT sting.

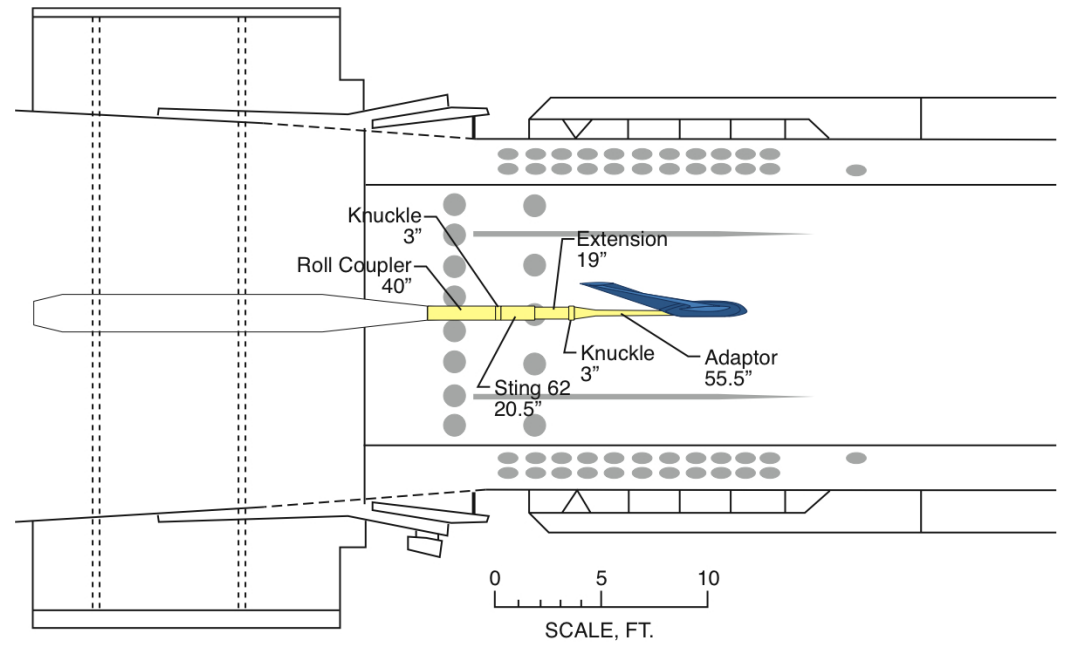

(b) Side view of TDT test section showing sting components and joined-wing model.

Figure 31. Joined-wing SensorCraft model installed on the TDT sting for Test 606 .

The bulk of the aerodynamic data acquired during Test 606 was steady and fell into three categories: 1) Alpha sweeps with various combinations of symmetric control surface deflections; 2) Beta sweeps at various alpha values with control surfaces fixed at zero; and 3) Symmetric and antisymmetric control surface deflection sweeps with model held at its expected trim attitude. These data sets are described in detail in reference 12. Overall, there were few surprises in the data, with lift and drag being well behaved linear and quadratic functions, respectively, of alpha. The forward wing control surfaces were effective at generating lift, but provided limited pitching moment. These forward wing control surface loads were also found to be relatively linear. The only unusual finding was the lift and pitching moment associated with aft wing control surfaces. As shown in figure 32 the normal force and pitching moment are nonlinear especially between deflections of $-10^{\circ}$ and $0^{\circ}$. This behavior is likely due to the aft wing's relatively thick airfoil. It is also believed that this nonlinear behavior had a slight destabilizing effect on the trim controller stability margins. 


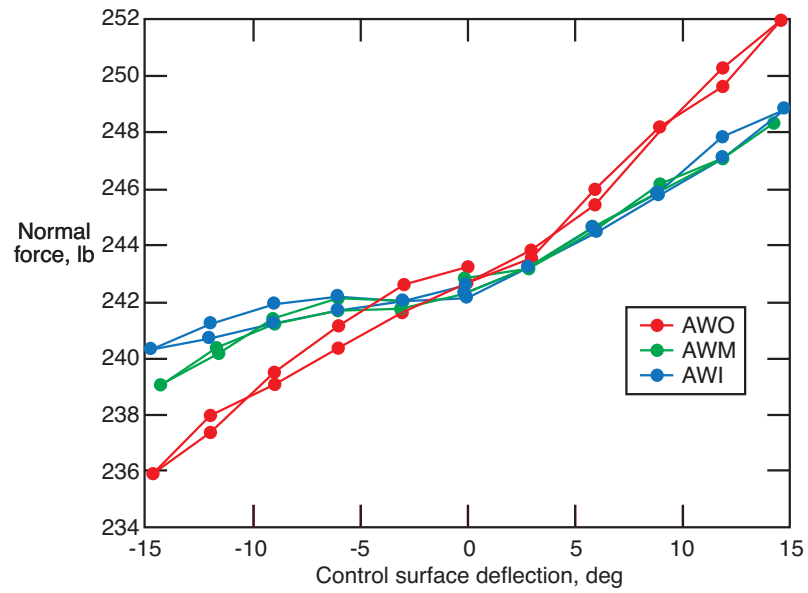

(a) Normal force.

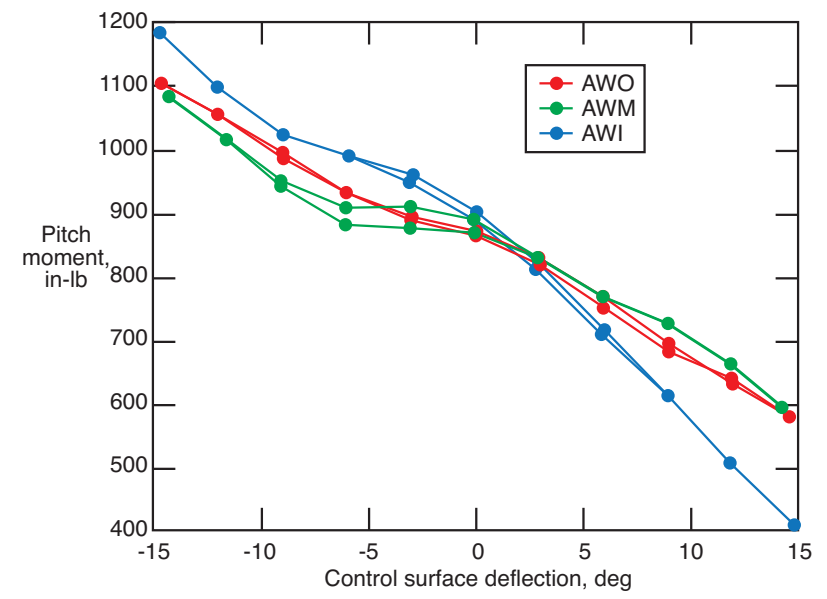

(b) Pitching moment.

Figure 32. Normal force and pitching moment associated with aft wing control surface deflections. 